\title{
PPAR $-\gamma$ agonist rosiglitazone protects peritoneal membrane from dialysis fluid-induced damage
}

\author{
Pilar Sandoval ${ }^{1,9}$, Jesús Loureiro ${ }^{1,9}$, Guadalupe González-Mateo², Maria L Pérez-Lozano ${ }^{1}$, \\ Alejandra Maldonado-Rodríguez', José A Sánchez-Tomero ${ }^{3}$, Lorea Mendoza ${ }^{4}$, Beatriz Santamaría ${ }^{5}$, \\ Alberto Ortiz ${ }^{5}$, Marta Ruíz-Ortega ${ }^{5}$, Rafael Selgas ${ }^{2}$, Pilar Martín ${ }^{6}$, Francisco Sánchez-Madrid ${ }^{6,7}$, Abelardo Aguilera ${ }^{1}$ \\ and Manuel López-Cabrera ${ }^{1,8}$
}

Exposure to non-physiological solutions during peritoneal dialysis (PD) produces structural alterations to the peritoneal membrane and ultrafiltration dysfunction. The high concentration of glucose and glucose degradation products in standard PD fluids induce a local diabetic environment, which leads to the formation of advanced glycation end products (AGEs) that have an important role in peritoneal membrane deterioration. Peroxisome proliferator-activated receptor $\gamma$ (PPAR- $\gamma$ ) agonists are used to treat type II diabetes and they have beneficial effects on inflammation, fibrosis, and angiogenesis. Hence, we evaluated the efficacy of the PPAR- $\gamma$ agonist rosiglitazone (RSG) in ameliorating peritoneal membrane damage in a mouse PD model, and we analyzed the mechanisms underlying the protection offered by RSG. Exposure of the peritoneum to PD fluid resulted in AGEs accumulation, an inflammatory response, the loss of mesothelial cell monolayer and invasion of the compact zone by mesothelial cells, fibrosis, angiogenesis, and functional impairment of the peritoneum. Administration of RSG diminished the accumulation of AGEs, preserved the mesothelial monolayer, decreased the number of invading mesothelial cells, reduced fibrosis and angiogenesis, and improved peritoneal function. Interestingly, instead of reducing the leukocyte recruitment, RSG administration enhanced this process and specifically, the recruitment of CD3 ${ }^{+}$lymphocytes. Furthermore, RSG treatment augmented the levels of the antiinflammatory cytokine interleukin (IL)-10 and increased the recruitment of $\mathrm{CD}^{+} \mathrm{CD}_{2} 5^{+} \mathrm{FoxP}^{+}$cells, suggesting that regulatory T cells mediated the protection of the peritoneal membrane. In cell-culture experiments, RSG did not prevent or reverse the mesothelial to mesenchymal transition, although it decreased mesothelial cells apoptosis. Accordingly, RSG appears to produce pleiotropic protective effects on the peritoneal membrane by reducing the accumulation of AGEs and inflammation, and by preserving the mesothelial cells monolayer, highlighting the potential of PPAR- $\gamma$ activation to ameliorate peritoneal deterioration in PD patients.

Laboratory Investigation (2010) 90, 1517-1532; doi:10.1038/labinvest.2010.111; published online 7 June 2010

KEYWORDS: advanced glycation end products; fibrosis; mesothelial to mesenchymal transition; peritoneal dialysis; regulatory T cells; rosiglitazone

Peritoneal dialysis (PD) is a renal replacement strategy based on the use of the peritoneum as a semi-permeable membrane across which ultrafiltration and diffusion take place. ${ }^{1,2}$ The morphology of the peritoneal membrane is simple as it is comprised of a single layer of mesothelial cells that covers a submesothelial region composed of connective tissue containing a few fibroblasts, mast cells, macrophages, and vessels. ${ }^{3}$ Mesothelial cells are the key regulators of peritoneal homeostasis, and they participate in peritoneal immune and inflammatory responses, providing protection against invading microbes. ${ }^{3,4}$ Chronic exposure to non-physiological PD solutions and episodes of infection cause inflammation and damage to the peritoneal membrane, which undergoes a loss of the mesothelial cells monolayer, submesothelial

\footnotetext{
${ }^{1}$ Unidad de Biología Molecular, Hospital Universitario de la Princesa, Madrid, Spain; ${ }^{2}$ Unidad de Investigación and Servicio de Nefrología, Hospital Universitario La Paz, Madrid, Spain; ${ }^{3}$ Servicio de Nefrología, Hospital Universitario de la Princesa, Madrid, Spain; ${ }^{4}$ Pharmakine SL, Derio, Vizcaya, Spain; ${ }^{5}$ Unidad de Diálisis and Laboratorio de Investigación Renal y Vascular, Fundación Jiménez Díaz, Madrid, Spain; ' ${ }^{6}$ epartment of Vascular Biology and Immunology, Centro Nacional de Investigaciones Cardiovasculares, Madrid, Spain; ${ }^{7}$ Servicio de Inmunología. Hospital Universitario de la Princesa, Madrid, Spain and ${ }^{8}$ Department of Cellular Biology and Immunology, Centro de Biología Molecular Severo Ochoa, CSIC-UAM, Cantoblanco, Madrid, Spain

Correspondence: Dr M López-Cabrera, PhD, Unidad de Biología Molecular, Hospital Universitario de la Princesa, C/Diego de León n 62, Madrid 28006, Spain. E-mail: mlopez.hlpr@salud.madrid.org

${ }^{9}$ These authors contributed equally to this work. 
fibrosis, angiogenesis and hyalinizing vasculopathy. ${ }^{5-7}$ These morphological alterations are associated with increased rates of small-solute transport and with ultrafiltration dysfunction of the peritoneal membrane. ${ }^{3,5,8}$ The patho-physiological mechanisms underlying the peritoneal structural and functional impairment are still not fully clear. Inflammatory cells and myofibroblasts are considered to be mainly responsible for peritoneal membrane deterioration during long-term PD. ${ }^{3,9}$ It has been shown that myofibroblasts may arise from local conversion of mesothelial cells through a mesothelial to mesenchymal transition (MMT) that is induced during the inflammatory and repair responses provoked by PD. ${ }^{3,10-12}$ The MMT is a complex process that is characterized by the disruption of intercellular junctions, adoption of a frontback polarity and an increase in migratory/invasive capacity, which allow mesothelial cells to invade the submesothelial compact zone. ${ }^{3,13}$ In addition, trans-differentiated mesothelial cells acquire the capacity to synthesize pro-inflammatory and pro-angiogenic factors, as well as extracellular matrix components, thereby contributing to the deterioration of the peritoneal membrane. In this context, it has been shown that the presence of trans-differentiated mesothelial cells, either in the PD effluent or peritoneal tissue of PD patients, is correlated with high transport rates. ${ }^{14-16}$

Glucose, used as an osmotic agent in most common PD fluids, and glucose degradation products, generated during heat sterilization and storage, induce a local diabetic environment within the peritoneal cavity through the generation of advanced glycation end products (AGEs). ${ }^{17}$ AGEs have been associated with the progress and complications of diabetes, ${ }^{18}$ and they may act directly to induce cross-linking of long-lived proteins like collagen, altering vascular structure and function. AGEs may also interact with certain receptors, such as the receptor of AGEs (RAGE), activating intracellular signals that produce oxidative stress and the synthesis of pro-inflammatory cytokines. ${ }^{18}$ Several studies have demonstrated the presence of AGEs in both the peritoneal effluent and peritoneal tissue of $\mathrm{PD}$ patients and the intensity of AGEs accumulation is associated with the length of time on PD, the extent of fibrosis and peritoneal membrane functional decline. ${ }^{9}$

The peroxisome proliferator-activated receptor- $\gamma(\operatorname{PPAR}-\gamma)$ is a member of the nuclear hormone receptor family that has a key role in the regulation of lipid and glucose homeostasis. ${ }^{19}$ PPAR- $\gamma$ agonists control glycemia by improving insulin sensitivity, which has led to their use in treating type II diabetes. ${ }^{20,21}$ Besides their glucose-lowering effects, PPAR- $\gamma$ agonists also have anti-inflammatory properties by modulating both innate and adaptive immune responses and by activating a regulatory T-cell response. ${ }^{22-27}$ Probably as a consequence of these multiple anti-inflammatory actions, PPAR- $\gamma$ ligands have demonstrated anti-fibrotic effects in several experimental models, including diabetic and nondiabetic chronic kidney diseases. ${ }^{28-31}$ It has been described that PPAR- $\gamma$ agonists improve renal function in patients with incipient diabetic nephropathy. ${ }^{32}$ However, the potential protective effects for the peritoneal membrane of agents that activate PPAR $\gamma$ have not been explored in depth. It has been shown that Rosiglitazone (RSG) ameliorates some of the peritoneal functional and morphological alterations in rat models of encapsulating peritoneal sclerosis and dialysis fluid exposure, ${ }^{33,34}$ although the mechanisms underlying PPAR- $\gamma$ mediated protection of the peritoneal membrane remain largely unknown.

Here, we show that administration of RSG to mice exposed to PD fluid decreased the accumulation of AGEs, and preserved peritoneal morphology and function. Moreover, RSG administration enhanced the recruitment of $\mathrm{CD} 4{ }^{+} \mathrm{CD} 25^{+}$ FoxP3 ${ }^{+}$regulatory $\mathrm{T}$ cells to the peritoneal cavity and augmented the levels of the anti-inflammatory cytokine IL-10. RSG did not affect the MMT in vitro, but it protected mesothelial cells from PD fluid-induced cell death. Thus, RSG may have pleiotropic protective effects on the peritoneal membrane, reducing AGEs formation and inflammation, and preserving the mesothelial cells monolayer.

\section{MATERIALS AND METHODS \\ Peritoneal Dialysis Fluid Exposure Model in Mice}

A total of 42 female C57BL/6 mice aged between 12 and 16 weeks old were used in this study (Harlan Interfauna Iberica, Barcelona, Spain). The experimental protocol used was in accordance with the National Institutes of Health Guide for Care and Use of Laboratory Animals and was approved by the Animal Ethics Committee of the 'Unidad de Cirugía Experimental' of 'Hospital Universitario la Paz'. PD fluid or saline solution were instilled via a peritoneal catheter connected to an implanted subcutaneous mini access port (Access Technologies, Skokie, IL, USA) as previously described. ${ }^{15,35}$ Mice that were not treated surgically and that received no fluid, served as control group (Control; $n=5$ ). During the first week after surgery, the animals implanted with a peritoneal access port $(n=37)$ received $0.2 \mathrm{ml}$ of saline with $1 \mathrm{IU} / \mathrm{ml}$ heparin to facilitate wound healing. Thereafter, during a 3-week period, seven mice were daily instilled with $1.5 \mathrm{ml}$ of saline solution (saline group; $n=7$ ), 15 mice were daily instilled with $1.5 \mathrm{ml}$ of standard PD fluid composed of $4.25 \%$ glucose and buffered with lactate (Stay Safe; Fresenius, Bad Homburg, Germany) (PDF group) and 15 mice were daily instilled with $1.5 \mathrm{ml}$ of standard PD fluid and orally treated with RSG (20 mg/kg/day) (PDF + RSG group). Three animals in the PDF group and four in the PDF + RSG group were not used in the final analysis, being the main causes of drop-outs catheter port infection or traumatic catheter removal (PDF group, $n=12$; PDF + RSG; group, $n=11$ ). In all the cases, during the last day of treatment the immunoinflammatory cells were collected from the peritoneal cavity for flow cytometry analysis. The whole study was performed in two separated experiments. In one experiment a peritoneal equilibrium test was performed during the last day of treatments. Mice were instilled with $1.5 \mathrm{ml}$ of PD solution and 
30 min later animals were anaesthetized to obtain a blood sample by cardiac puncture and killed to recover the total peritoneal volumes. Glucose concentrations in sera were determined by using the Glucocard G + meter device (Arkray Factory, Shiga, Japan).

\section{Flow Cytometry and Immunohistochemical Analyses}

In one experiment, the peritoneal immuno-inflammatory cell populations from mice treated with PD fluid with or without RSG were analyzed by flow cytometry using a FACS Canto II cytometer (BD Biosciences, Franklin Lakes, NJ, USA) and the following monoclonal antibodies: anti-CD4 (L3T4), anti-CD8 (Ly-2), anti-CD3, and anti-CD19 (BD Biosciences); and antiF4/80 (e-Bioscience, San Diego, CA, USA). Peritoneal IL-10 concentration was measured by ELISA (R\&D Systems, Minneapolis, MN, USA). In another experiment, the specific effect of RSG treatment on regulatory T-cell population in the peritoneal cavity was analyzed. Effluent-derived cellular suspensions from mice treated with PD fluid with or without RSG were sequentially filtered through 70- $\mu \mathrm{m}$ (BD Falcon) and 40$\mu \mathrm{m}$ (Miltenyi Biotec, Bergisch Gladbach, Germany) cell strainers. Intracellular labelling of the transcription factor Foxp3 by an anti-Foxp3 antibody (FJK-16s; e-Bioscience) was performed according to the manufacturer's recommendations. Cells were also labelled with anti-CD4 and anti-CD25 monoclonal antibodies (BD Biosciences). Isotype-irrelevant monoclonal antibodies were used as controls. Processed cells were analyzed with a flow cytometer. Further analyses were performed with FACS Diva software (BD Biosciences). The concentration of different cytokines, including IL-10, in these effluents were measured by flow cytometry using the Mouse Th1/Th2 10plex kit (Bender MedSystems GmbH, Vienna, Austria).

For immunohistochemical analysis, parietal peritoneum tissues were routinely fixed in Bouin's Liquid and embedded in paraffin to obtain serial tissue sections $3-4 \mu \mathrm{m}$ thick. Deparaffinized sections were stained with Masson's trichrome solution to analyze the histological characteristics of each specimen. The thickness of submesothelial tissue was determined by blinded microscope analysis using a metric ocular. Before immunohistochemistry, tissue sections were heated to expose the hidden antigens using Real Target Retrieval Solution containing citrate buffer, pH 6.0 (Dako, Glostrup, Denmark). Samples were also pre-treated with Real Peroxidase-Blocking Solution (Dako) to block the endogenous peroxidase. The Dako REAL EnVision Detection System, Peroxidase/DAB +, Rabbit/Mouse (Dako) was applied to detect the following primary mouse monoclonal antibodies: anti- $\alpha$-SMA (clone 1A4; Sigma-Aldrich, St Louis, MO, USA); anti-pan-cytokeratin (clone PCK-26; SigmaAldrich); anti-CD31 (clone JC70A; Dako); and anti-AGEs (clone 6D12; Cosmo Bio, Tokyo, Japan). In all cases, primary antibodies were incubated for $1 \mathrm{~h}$, at room temperature, in a humid chamber, having previously blocked non-specific binding of the secondary antibody by pre-treating the slides for 15 min with goat serum. A biotinylated rabbit anti-rat IgG
$(\mathrm{H}+\mathrm{L})$, was applied to detect the rat anti-mouse CD45 primary monoclonal antibody (clone 30-F11; BD Biosciences), and this complex was visualized using the RTU Vectastain Elite ABC Kit (Vector Laboratories, Burlingame, CA, USA) having blocked non-specific binding for $15 \mathrm{~min}$ with rabbit serum. In dual immunohistochemistry, the EnVision G/2 Doublestain System, Rabbit/Mouse DAB + / Permanent Red (Dako) was used to detect $\alpha$ SMA (Brown) and cytokeratins (Red) simultaneously. All tissue sections were finally counterstained lightly with nuclear hematoxylin staining. $\mathrm{CD} 31^{+}$capillaries, $\mathrm{CD} 45^{+}$cells and AGEs staining of 10 arbitrary fields per sample $(\times 40)$ were quantified using the analysis program Image-J 1.37c (National Institute of Health, Bethesda, Maryland, USA).

\section{Isolation and Culture of Mesothelial Cells and Treatments}

Human mesothelial cells were obtained from omental samples of patients undergoing unrelated abdominal surgery and from effluents of PD patients as previously described. ${ }^{10,14,15}$ Cells were cultured in Earle's M199 medium supplemented with $20 \%$ fetal calf serum, $50 \mathrm{U} / \mathrm{ml}$ penicillin, $50 \mu \mathrm{g} / \mathrm{ml}$ streptomycin, and 2\% Biogro-2 (containing insulin, transferrin, ethanolamine, and putrescine: Biological Industries, Beit Haemek, Israel). The purity of omentum and effluentderived mesothelial cell cultures was determined through the expression of the standard mesothelial markers, intercellular adhesion molecule (ICAM)-1, calretinine and cytokeratins. These mesothelial cell cultures were negative for von-Willebrand factor and CD45 ruling out any contamination by endothelial cells or macrophages. To induce MMT in vitro, omentum-derived mesothelial cells were seeded on wells coated with $50 \mu \mathrm{g} / \mathrm{ml}$ of collagen I (Roche Diagnostics $\mathrm{GmbH}$, Mannheim, Germany) and treated for $48 \mathrm{~h}$ with $1 \mathrm{ng} / \mathrm{ml}$ of human-recombinant transforming growth factor $\beta 1$ (TGF- $\beta 1$ : R\&D Systems), which has been proven to be a good in vitro model of MMT. ${ }^{10,14,15}$ Where indicated, RSG (GlaxoSmithKline, Brentford, Middlesex, UK) was used at concentrations ranging from 0.1 to $10 \mu \mathrm{M}$. This study adjusts to the Declaration of Helsinki and it was approved by the Ethics Committee of 'Hospital Universitario de la Princesa' (Madrid, Spain). Informed written consent to use effluent samples was obtained from all the PD patients included in this study and oral informed consent was obtained from omentum donors subjected to elective surgeries.

\section{Western Blot, Real-Time Quantitative RT-PCR and Enzyme-Linked Immunoassays}

For western blotting, mesothelial cell cultures were lysed in a buffer $(1 \%$ sodium deoxycholate, $0.1 \%$ sodium dodecyl sulfate) and total protein quantified using a protein assays kit (Bio-Rad, Hercules, CA, USA). Cellular proteins $(50 \mu \mathrm{g})$ were resolved in $8-10 \%$ sodium dodecyl sulfate-polyacrylamide gels. Proteins were transferred on to nitrocellulose membranes, which were then blocked with fat free-milk and 
probed with specific antibodies against PPAR- $\gamma$ (Santa Cruz Biotechnology, Santa Cruz, CA, USA), E-cadherin, collagen I, $\alpha$-SMA, fibronectin and tubulin (Sigma-Aldrich). These antibodies were detected with a peroxidase conjugated goat anti-mouse IgG antibody (BD Biosciences) and visualized by enhanced chemilumniscence (ECL detection kit, Amersham Biosciences, Freiburg, Germany). Blot images were acquired with a LAS-1000 charge-coupled device camera (Fujifilm, Cedex, France).

Total RNA was extracted using TRI Reagent (Ambion, Austin, TX, USA) and complementary DNA was obtained by reverse transcription according to the manufacturer's recommendation (Applied Biosystems, Cheshire, UK). Quantitative PCR was carried out in a LightCycler 2.0 using a SYBR Green kit (Roche Diagnostics $\mathrm{GmbH}$ ) and specific primers for Snail, E-cadherin, Cox-2, and histone H3. ${ }^{10,15}$ Samples were normalized with respect to the value obtained for H3. Vascular endothelial growth factor (VEGF) concentration in culture supernatants was measured by ELISA (R\&D Systems). ${ }^{14}$

\section{Effect of RSG on Wound Healing, Cell Cycle and Apoptosis}

To test the effect of RSG on wound repair capacity of mesothelial cells, a wound heading experiment was performed with cells treated or not with $10 \mu \mathrm{M}$ of RSG, as previously described. ${ }^{10}$ Briefly, mesothelial cells from omentum, treated or not with RSG, were subjected to mechanical injury with an adapted cell scraper approximately $1500 \mu \mathrm{m}$ wide and they were photographed every $8 \mathrm{~h}$ over 2 days. As shown in Supplementary Figure S3, mesothelial cells had similar wound healing capacity at 24 and $48 \mathrm{~h}$ in the presence or absence of RSG.

To analyze the effect of RSG on cell cycle profile, mesothelial cells were grown in the presence or absence of $20 \%$ fetal calf serum and exposed to different doses of RSG $(0,1$, 10 and $100 \mu \mathrm{M})$ for $48 \mathrm{~h}$. The cells were harvested and fixed with $70 \%$ cold ethanol for $30 \mathrm{~min}$. After washing, samples were suspended in PBS and an equal volume of a solution containing $200 \mu \mathrm{g} / \mathrm{ml}$ RNase (Sigma-Aldrich), $20 \mu \mathrm{g} / \mathrm{ml}$ propidium iodide (Sigma-Aldrich), and $0.1 \%$ Triton X-100 was added to the cell suspension for $30 \mathrm{~min}$ at room temperature. A FACS Calibur flow cytometer (BD Bioscience) was used to analyze DNA content with emitted light measured at $675 \mathrm{~nm}$. As shown in Supplementary Table S1, there were no significant differences in cell cycle (M1 to M4) between control and RSG-treated cells.

To analyze the effect of RSG on apoptosis, mesothelial cells were cultured to subconfluence in 12-well plates (BD Bioscience) and transferred to serum-free media for $24 \mathrm{~h}$. The cells were pre-incubated with RSG $(0.1,1$, and $10 \mathrm{mM})$ or vehicle for $1 \mathrm{~h}$ and treated with $100 \mathrm{nM}$ Staurosporine for $24 \mathrm{~h}$. In other experiments, cells were pre-treated with RSG or vehicle for $1 \mathrm{~h}$ and then one volume of PD solution $(4.25 \%$ glucose, stay safe; Fresenius) or serum-free RPMI 1640 was added to the cells for $72 \mathrm{~h}$. To quantify cell death, the cells were harvested by pooling non-adherent cells with the adherent cells detached by mild trypsinization. Apoptosis was quantified assessing the DNA content by flow cytometry using Cellquest software (BD Biosciences). ${ }^{36,37}$

\section{Statistical Analysis}

Results are presented as 25th and 75th percentiles, median, minimum, and maximum values in box plots graphics of Figures 1, 2, 4-7. In Figures 8-10, bar graphics depict mean \pm s.e. or mean \pm s.d. The data groups were compared with the non-parametric Mann-Whitney rank sum $U$-test using the SPSS statistic package version 14.5 (Chicago, IL, USA) and GraphPad Prism version 4.0 (La Jolla, CA, USA). $P<0.05$ was considered statistically significant.

\section{RESULTS \\ RSG Ameliorates PD-Induced Peritoneal Membrane Structural and Functional Alterations}

PPAR- $\gamma$ agonists have both glucose-lowering effects and anti-inflammatory properties. ${ }^{20}$ Thus, we analyzed whether the PPAR- $\gamma$ agonists RSG might prevent the deterioration of the peritoneal membrane in a mouse model of PD fluid exposure. Mice were instilled daily with standard lactatebased PD fluid via catheters and orally administered RSG or the vehicle alone for 3 weeks. Animals that were not treated surgically and that received no fluid (control group) and animals that were daily instilled with saline solution via catheters (saline group) served as baselines throughout the whole study. Histological analysis of parietal peritoneum biopsies showed that PDF fluid exposure produced a loss of mesothelial cells monolayer and an increase in the peritoneal membrane thickness compared with control group (Figure 1) and with saline group (data not shown). Administration of RSG to PD fluid-treated mice significantly reduced the peritoneal thickness and preserved the mesothelium (Figure 1). To test the effect of RSG on PDF-induced angiogenesis, blood vessels of parietal peritoneum were stained with an anti-CD31 antibody. There was a significant increase in the number of vessels in PD fluid-instilled mice when compared with the control mice and with the saline group (not shown), and administration of RSG to PD fluid-instilled mice significantly reduced this angiogenesis (Figure 2). Another characteristic histological change of the peritoneal membrane during PD is the accumulation of myofibroblasts ( $\alpha$ SMA-positive fibroblasts) in the compact zone, which might be derived from the activation of resident fibroblasts and from local conversion of mesothelial cells via MMT., ${ }^{3,12}$ In the normal peritoneum from control mice, there was no expression of $\alpha \mathrm{SMA}$ other than that in the smooth muscle cells of the vessel walls and the expression of cytokeratin was limited to the mesothelium (Figures $3 \mathrm{a}$ and $\mathrm{b}$ ). By contrast, myofibroblasts were present in the submesothelial compact zone of mice treated with PD fluid (Figure 3c). A remarkable finding was the clustering tendency of myofibroblasts, mainly 

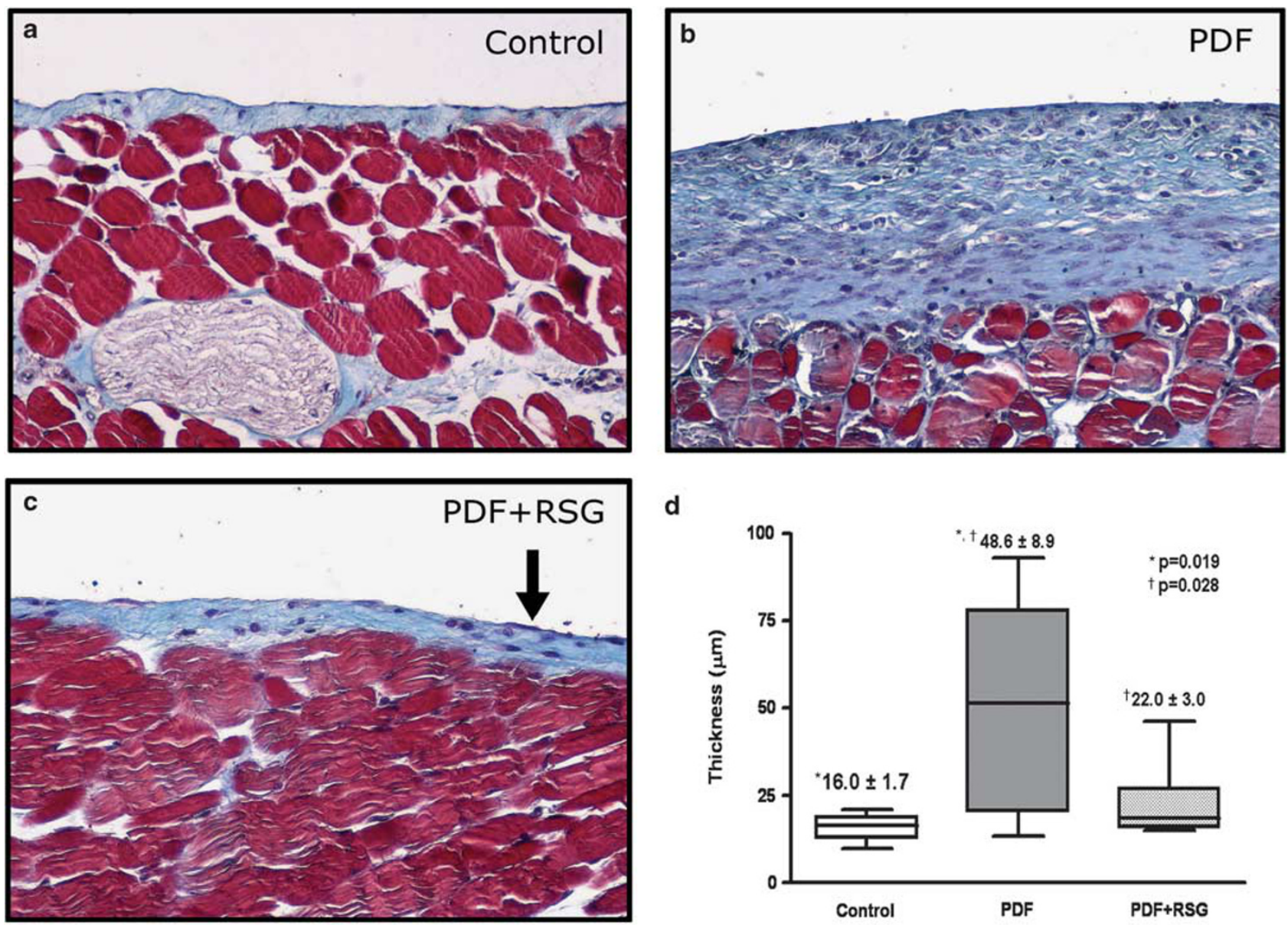

Figure 1 RSG treatment decreases PD-induced peritoneal membrane thickness in a mouse model. Mice received a daily instillation of standard PD fluid for 3 weeks with or without the oral administration of RSG $(20 \mathrm{mg} / \mathrm{kg} /$ day: PDF, $n=12$ and PDF + RSG $n=11)$. A control group of mice that were not surgically treated and received no fluid instillation was also included (control; $n=5$ ). Peritoneal samples were prepared and analyzed as described in the Materials and Methods. (a-c) Standard PD fluid exposure increases matrix deposition and the thickness of the peritoneal membrane, while RSG administration significantly reduces these effects when measured in Masson's trichrome stained sections (representative slides)). Arrow in panel $\mathbf{c}$ shows the preservations of the mesothelium in an RSG-treated animal. (d) Box plots graphic represent 25 th and 75 th percentiles, median, minimum and maximum values. Numbers above boxes depict mean \pm s.e. Symbols represent the statistic differences between groups. Magnification $\times 200$.

restricted to the upper submesothelial area, near the mesothelial surface, but in some cases, especially those with prominent fibrosis, myofibroblasts also accumulated in the deeper compact zone (Figure 3c). In many of these clusters, myofibroblasts co-expressed cytokeratin, indicative of their mesothelial origin (Figure 3d). Interestingly, PD fluidinstilled mice treated with RSG showed decreased submesothelial expression of $\alpha \mathrm{SMA}$ and the expression of cytokeratin was almost exclusively restricted to the preserved mesothelium (Figures 3e and f).

To analyze the functional relevance of the observed morphological changes of the peritoneum, a peritoneal equilibration test was performed on the last day of treatments. Mice of the saline, PDF and PDF + RSG groups were instilled with $1.5 \mathrm{ml}$ of $\mathrm{PD}$ solution and $30 \mathrm{~min}$ later the total peritoneal volumes were recovered and blood samples were obtained by cardiac puncture. As shown in Figure 4a, the volumes recovered from PD fluid-exposed animals were lower than those from saline-treated mice and a significant increase of volumes recovered was obtained in mice exposed to PD fluid that were administrated RSG. In addition, PD fluid-exposed mice showed a marked increase of the glucose concentrations in sera, compared with the saline group, and a partial normalization of glucose levels was observed in PD fluid-exposed animals treated with RSG (Figure $4 \mathrm{~b}$ ). These results demonstrated that RSG ameliorated the deleterious effects of PD fluid on the peritoneum, reducing fibrosis and angiogenesis and ultimately, improving peritoneal membrane function.

\section{Effects of RSG Treatment on PD-Induced AGEs Accumulation and Inflammation}

Peritoneal accumulation of AGEs and inflammation are early side effects of PD fluid exposure, which in turn may induce 
MMT of mesothelial cells, the accumulation of matrix components, angiogenesis and ultimately, peritoneal membrane dysfunction. ${ }^{3}$ Thus, we analyzed if RSG treatment affected the formation of AGEs and inflammatory response. As expected, PD fluid-instilled mice accumulated AGEs more intensely in the compact submesothelium than control mice or saline-instilled animals (not shown), and the administration of RSG to PD fluid-treated mice significantly reduced AGEs formation (Figure 5).

To test the effect of RSG on PD fluid-induced recruitment of leukocytes, parietal peritoneum samples were stained with an anti-CD45 antibody. There appeared to be an increase of
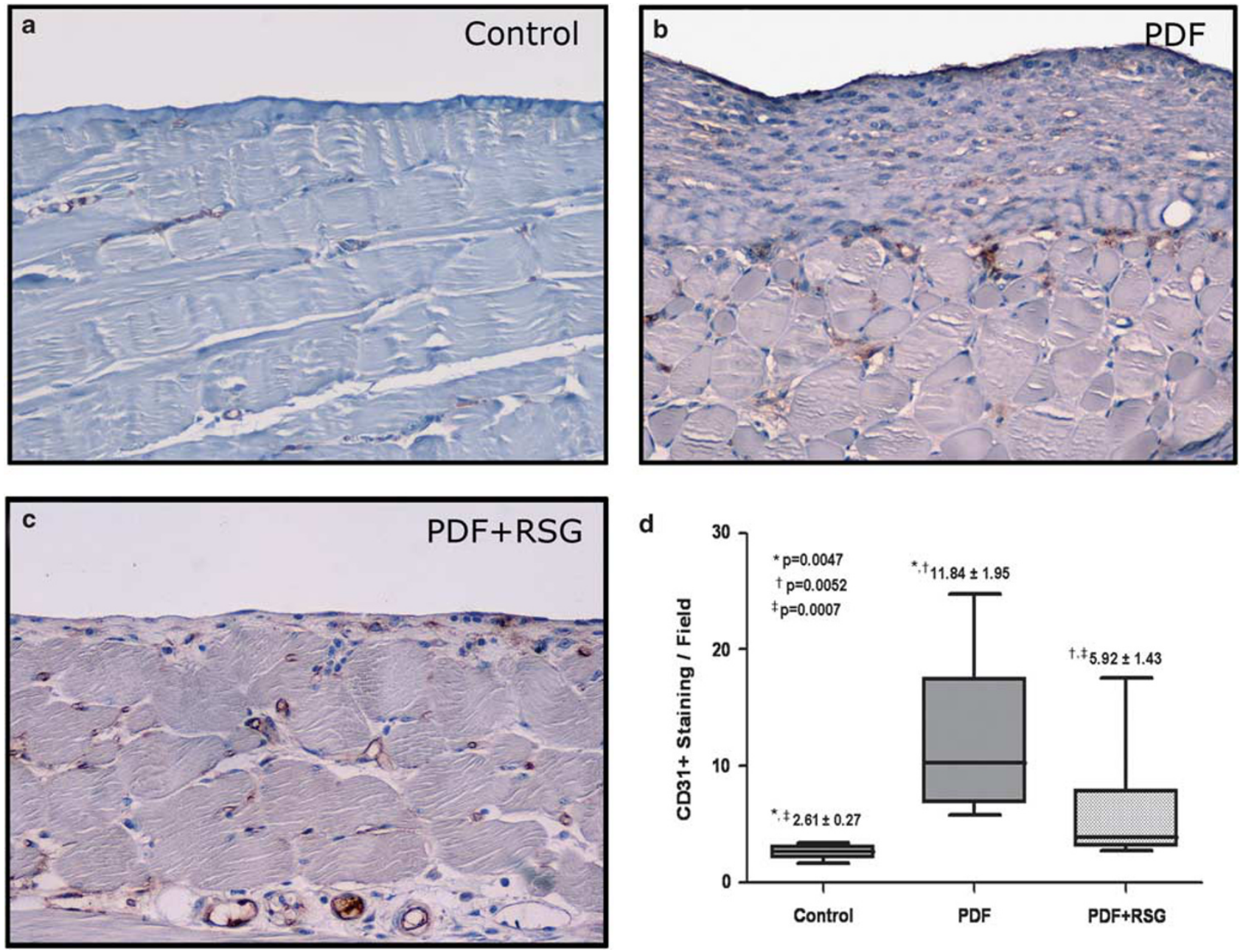

Figure 2 RSG treatment decreases PD-induced angiogenesis in the parietal peritoneum. Mice received a daily instillation of standard PD fluid for 3 weeks with or without the oral administration of RSG (PDF, $n=12$ and PDF $+\mathrm{RSG}, n=11)$. A control group of mice that were not surgically treated and that received no fluid was also included (Control; $n=5)$. (a-c) Standard PD fluid exposure increases peritoneal angiogenesis and RSG treatment significantly reduces the number of vessels, as determined by CD31 staining (representative slides). (d) Box plots of the median, minimum and maximum values, as well as the 25 th and 75 th percentiles. Numbers above boxes depict mean \pm s.e. Symbols represent the statistical differences between groups. Magnification $\times 200$.

Figure 3 Effects of RSG on submesothelial expression of $\alpha$ SMA and on mesothelial-mesenchymal transition (MMT) in vivo. (a, c and e) Staining with anti$\alpha$ SMA shows that there is no expression of $\alpha$ SMA in the parietal peritoneum of control mice other than in smooth muscle cells of the vessel walls (a). In mice treated with PD fluid, myofibroblasts are present and they tend to cluster in the submesothelial compact zone (c). PD fluid-instilled mice treated with RSG have weaker submesothelial expression of $\alpha \mathrm{SMA}(\mathbf{e})$. (b, $\mathbf{d}$ and $\mathbf{f}$ ) Double staining with anti- $\alpha$ SMA (brown) and anti-cytokeratin (red) shows that in control mice the expression of cytokeratin is limited to the mesothelium (b). In mice treated with PD fluid, most upper myofibroblast clusters co-express cytokeratin, indicative of their mesothelial origin (d). In PD fluid-instilled mice treated with RSG, the expression of cytokeratin is almost exclusively restricted to the preserved mesothelium (f). Representative slides are presented. The inset figure in panel $\mathbf{d}$ shows a detail of the mesothelial cells co-expressing $\alpha$ SMA and cytokeratin, invading the submesothelial space. The arrow in panel $\mathbf{f}$ indicates the preserved mesothelium in RSG-treated animals. Magnification $\times 200$. 
leukocyte infiltration in PD fluid-instilled mice compared with control mice, although this was not statistically significant. Surprisingly, rather than reducing the presence of $\mathrm{CD}_{4} 5^{+}$cells, RSG administration further enhanced the accumulation of immuno-inflammatory infiltrates (Figure 6). The analysis of peritoneal influx of leukocytes in
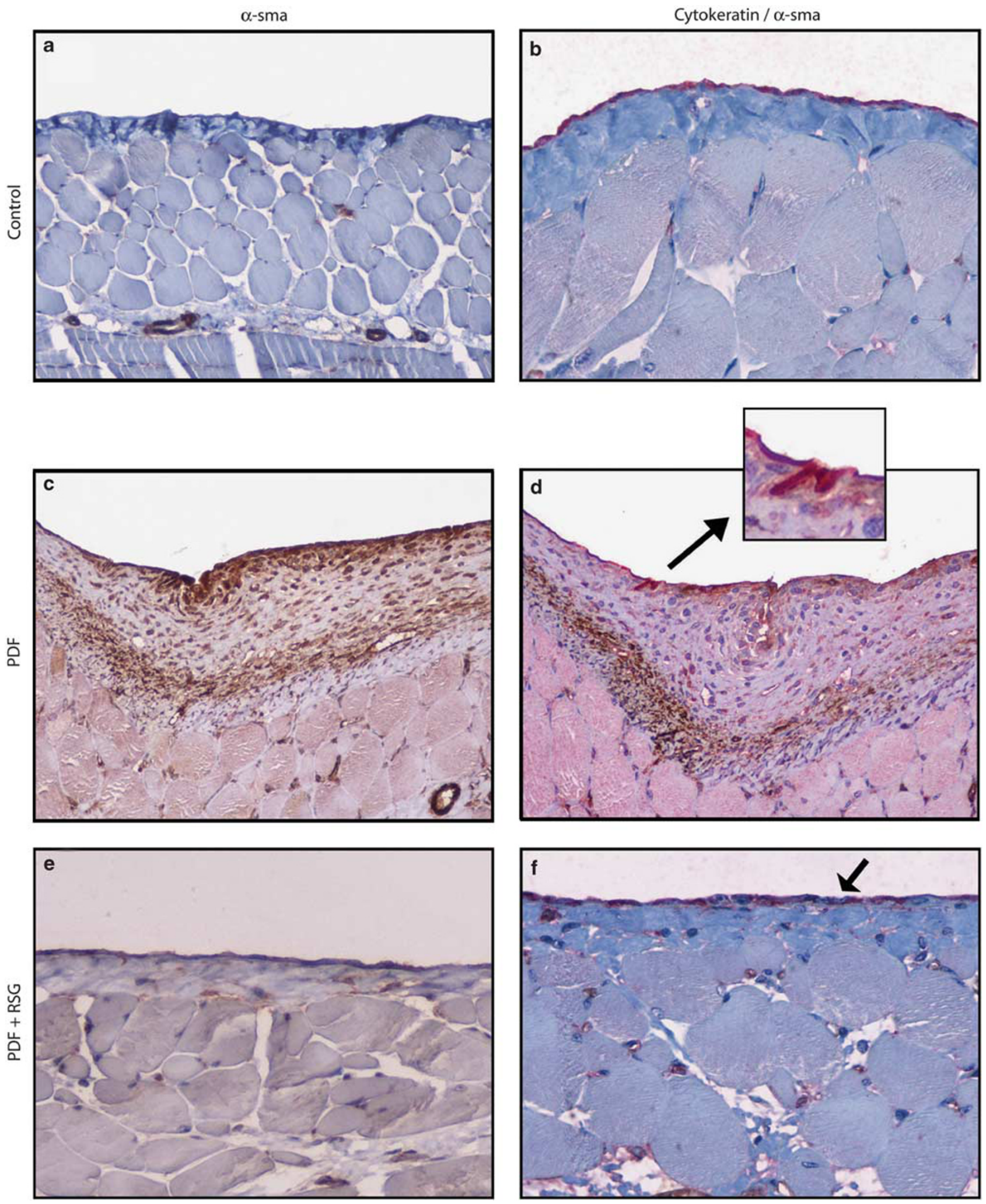

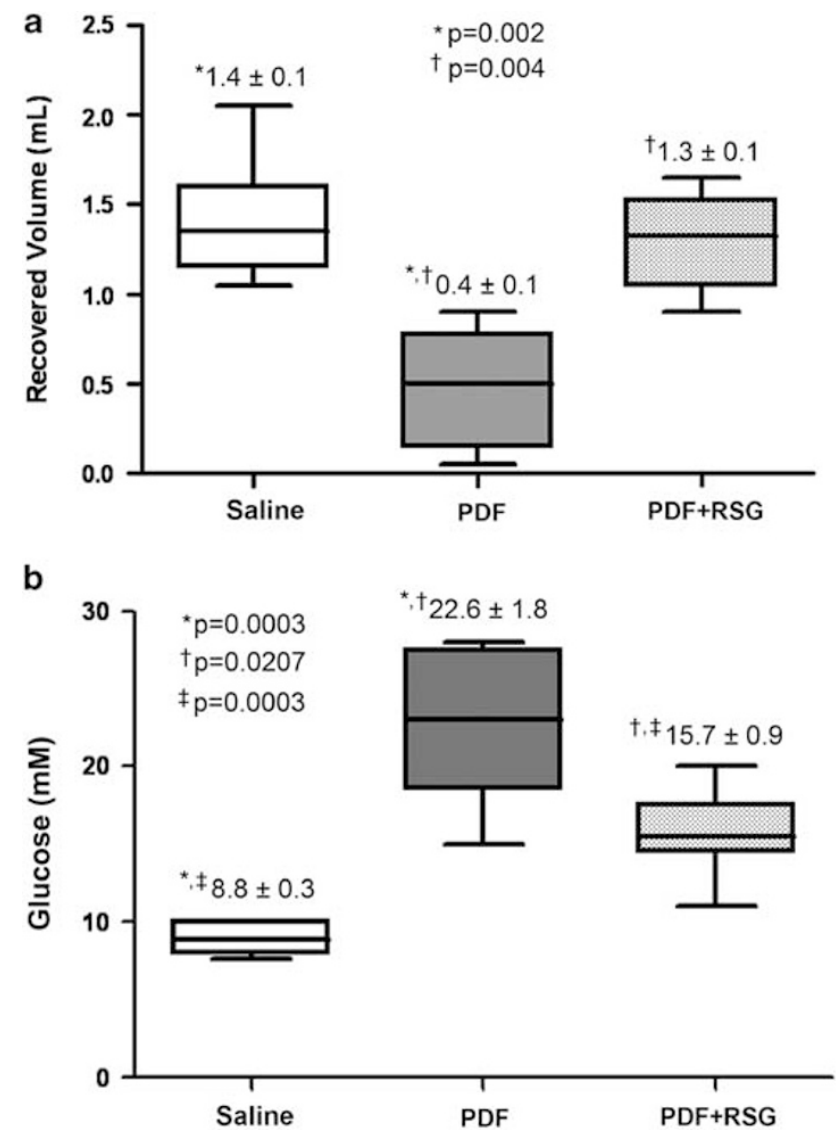

Figure 4 RSG treatment improves peritoneal ultrafiltration and lowers serum glucose concentration. A 30 min peritoneal equilibrium test was performed on the last day of treatments. (a) The volumes recovered from animals exposed to PD fluid (PDF; $n=5$ ) are lower than those from mice instilled with saline solution (saline; $n=7$ ), and a recovery of net ultrafiltration is obtained in mice exposed to PD fluid that were administrated RSG (PDF + RSG; $n=6$ ). (b) The glucose concentrations in sera are higher in animals exposed to PD fluid when compared with the saline group, and a partial normalization of glucose levels is observed in PD fluid-exposed animals treated with RSG. Box plot graphics represent 25th and 75th percentiles, median, minimum, and maximum values. Numbers above boxes depict mean \pm s.e. Symbols represent the statistic differences between groups.

the effluents also demonstrated a significant increase in the total cell count in PD fluid-instilled mice that were administrated RSG when compared with mice-treated PD fluid alone (Figure 7a). The increase in cell influx was more evident for T-cells $\left(\mathrm{CD}^{+}\right)$, and both T-lymphocytes populations, $\mathrm{CD}^{+}$and $\mathrm{CD}^{+}$, increased significantly (Figure $7 \mathrm{~b}-\mathrm{d}$ ). By contrast, the increase in B-lymphocytes $\left(\mathrm{CD} 19^{+}\right)$and macrophages $\left(\mathrm{F} 4 / 80^{+}\right)$did not reach statistical differences (Figure $7 \mathrm{e}$ and $\mathrm{f}$ ). Interestingly, the effluents from PD fluidinstilled mice treated with RSG had significantly higher concentration of the anti-inflammatory cytokine IL-10 than mice treated with PD fluid alone (Figure 8a). Other cytokines present in the effluents did not show significant differences between PD fluid-instilled animals treated or not with RSG
(Supplementary Figure S1), although there was a tendency to decrease the concentrations of the pro-inflammatory cytokines IL-6 and IL-17 and to increase the levels of the anti-inflammatory cytokine IL-4 in the group treated with RSG (Supplementary Figure S1). These data suggested that RSG administration modulated the inflammation, probably via enhancement of regulatory T-cells. To assess whether RSG treatment affected the regulatory $\mathrm{T}$ cell population in the peritoneal cavity, the $\mathrm{CD} 4{ }^{+} \mathrm{CD} 25^{+} \mathrm{FoxP} 3{ }^{+}$population in the drained volumes of the peritoneal equilibration test was analyzed by flow cytometry. There was a significant increase in the regulatory $\mathrm{T}$ cells population in $\mathrm{PD}$ fluid-instilled mice that were administrated RSG when compared with mice treated with PD fluid alone (Figures $8 \mathrm{~b}$ and $\mathrm{c}$ ). Together these results suggested that RSG administration ameliorated the deleterious effects of PD fluid exposure by reducing peritoneal accumulation of AGEs and by inducing a regulatory T-cell response to modulate inflammation.

\section{Effects of RSG on Mesothelial to Mesenchymal Transition and Cell Death In Vitro}

The MMT of mesothelial cells is an important process in peritoneal membrane dysfunction ${ }^{14-16}$ and treating PD fluid instilled mice with RSG resulted in a reduction of trans-differentiated mesothelial cells in the compact zone (Figure 3). Hence, we examined the effect of RSG on TGF- $\beta 1$ induced MMT of mesothelial cells in vitro. We first analyzed whether omentum-derived mesothelial cells expressed PPAR- $\gamma$, and how its expression was affected by TGF- $\beta 1$ and/or different doses of RSG. Mesothelial cells showed high levels of PPAR- $\gamma$ and its expression was downregulated by RSG in a dose-dependent manner $(0.1-10 \mu \mathrm{M})$, suggesting a negative feed-back regulation of this receptor (Figure 9a). TGF- $\beta 1$-induced PPAR- $\gamma$ expression in mesothelial cells exposed to different doses of RSG (Figure 9a). RSG did not prevent the TGF- $\beta 1$-induced morphological change or downregulation of E-cadherin (Figures $9 \mathrm{~b}$ and $\mathrm{c}$ ). In addition, RSG did not affect the upregulation of MMT-associated molecules including $\alpha \mathrm{SMA}$, the matrix components collagen I and fibronectin (Figure 9c), the proinflammatory molecule COX-2 (Figure 9d), the pro-angiogenic factor VEGF (Figure 9e) and the pro-inflammatory cytokines IL-6 and IL-8 (data not shown). Furthermore, RSG treatment was unable to revert the mesenchymal characteristics of effluent-derived mesothelial cells to an epitheliod phenotype (Supplementary Figure S2). These results suggested that PPAR- $\gamma$ signaling was not directly involved in controlling the mesenchymal conversion of mesothelial cells.

PPAR- $\gamma$ agonists are key regulators of cell proliferation and survival, and they have been attributed both pro-apoptotic and anti-apoptotic functions. ${ }^{38-43}$ Since we observed better preservation of the mesothelial cells monolayer in miceadministered RSG (Figures 1 and 3), we analyzed the role of this PPAR- $\gamma$ agonist in cell growth and apoptosis. Treatment of omentum-derived mesothelial cells with different doses of 

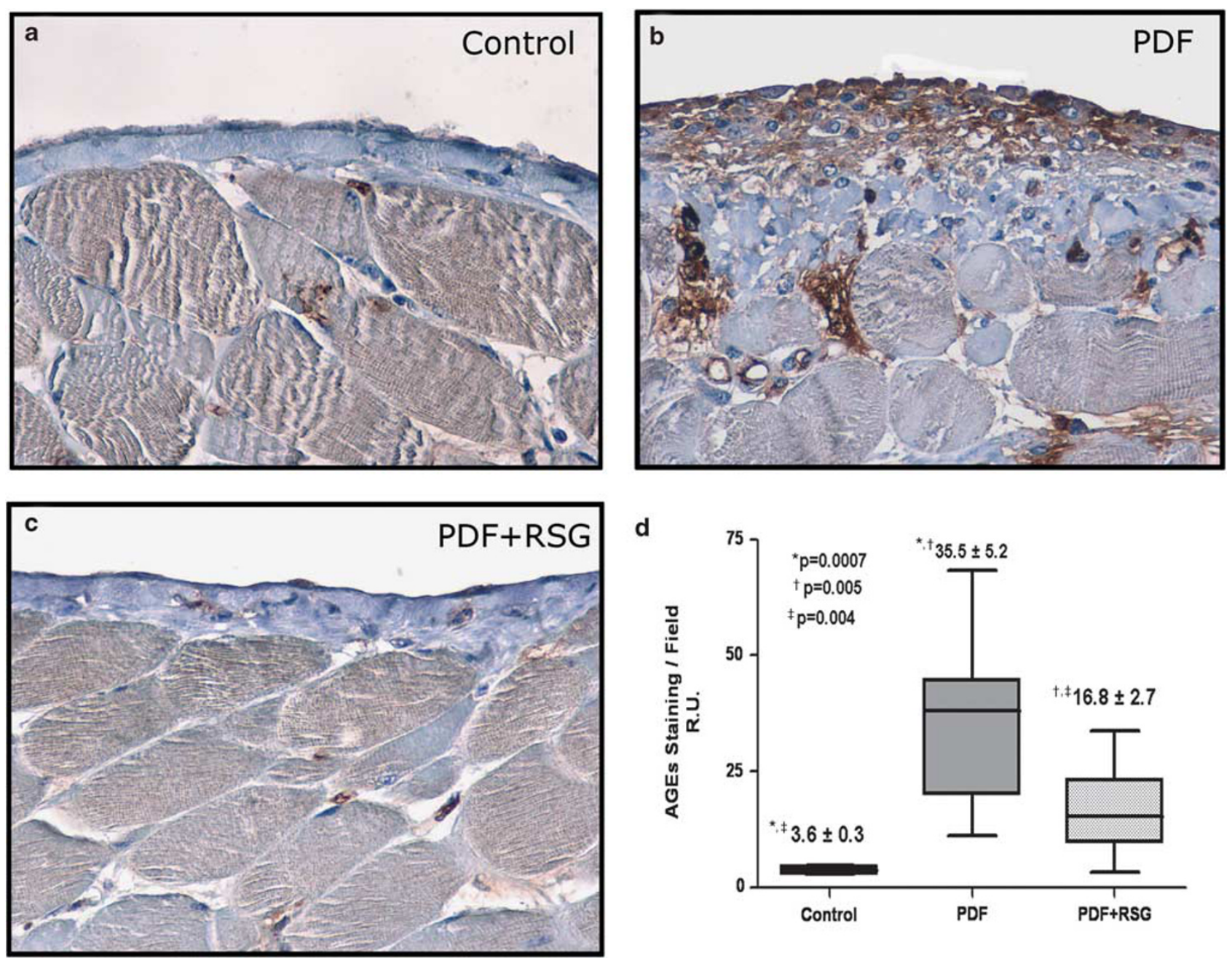

Figure 5 RSG treatment decreases the accumulation of AGEs induced by PD fluid. Mice received a daily instillation of standard PD fluid for 3 weeks with or without the oral administration of RSG (PDF, $n=12$ and PDF + RSG $n=11)$. A control group of mice that were not surgically treated and that received no fluid was also studied (control; $n=5)$. (a-c) PD fluid exposure results in the accumulation of AGEs in the parietal peritoneum, and RSG treatment significantly reduces this effect (representative slides). (d) Box plots of the median, minimum and maximum, as well as the 25th and 75th percentile values. Numbers above boxes depict mean \pm s.e. The symbols represent the statistical differences between groups. Magnification $\times 400$.

RSG did not affect cell cycle profile (Supplementary Table S1) and the wound healing capacity of these cells (Supplementary Figure S3). However, when mesothelial cells were subjected to two pro-apoptotic stimuli $(100 \mathrm{nM}$ of Staurosporine or PD fluid with high content of glucose and glucose degradation products), RSG provided partial protection from cell death (Figure 10). These results indicated that RSG was not cytotoxic for mesothelial cells and that rather, it produced an anti-apoptotic effect in these cells.

\section{DISCUSSION}

Damage to the peritoneum is a serious event in PD because it may jeopardize the organ on which the whole treatment is based. Therefore, one of the most important challenges in PD is to maintain the integrity of the peritoneal membrane. ${ }^{1,2}$ Exposing the peritoneum to PD fluids induces inflammation and a local diabetic environment, associated with the generation AGEs and the structural and functional deterioration of the peritoneal membrane. ${ }^{9}$ PPAR- $\gamma$ agonists have both anti-diabetic and anti-inflammatory properties ${ }^{20-27}$ and they have been associated with anti-fibrotic effects in several experimental models and in patients. ${ }^{28-32}$ However, the potential of PPAR- $\gamma$ agonists to act as therapeutic agents to ameliorate peritoneal membrane damage, as well as their mechanisms of action, have not yet been explored in depth. ${ }^{33,34}$

In this study, we show that oral administration of the PPAR- $\gamma$ agonist RSG ameliorates the peritoneal damage induced by PD fluids exposure in a newly developed mouse PD model. The positive effects of RSG include preservation of mesothelium, a reduction in fibrosis and angiogenesis in the parietal peritoneum and an improvement of membrane function. In a previous study, it has been shown that intraperitoneal administration of RSG to PD fluids-instilled rats 

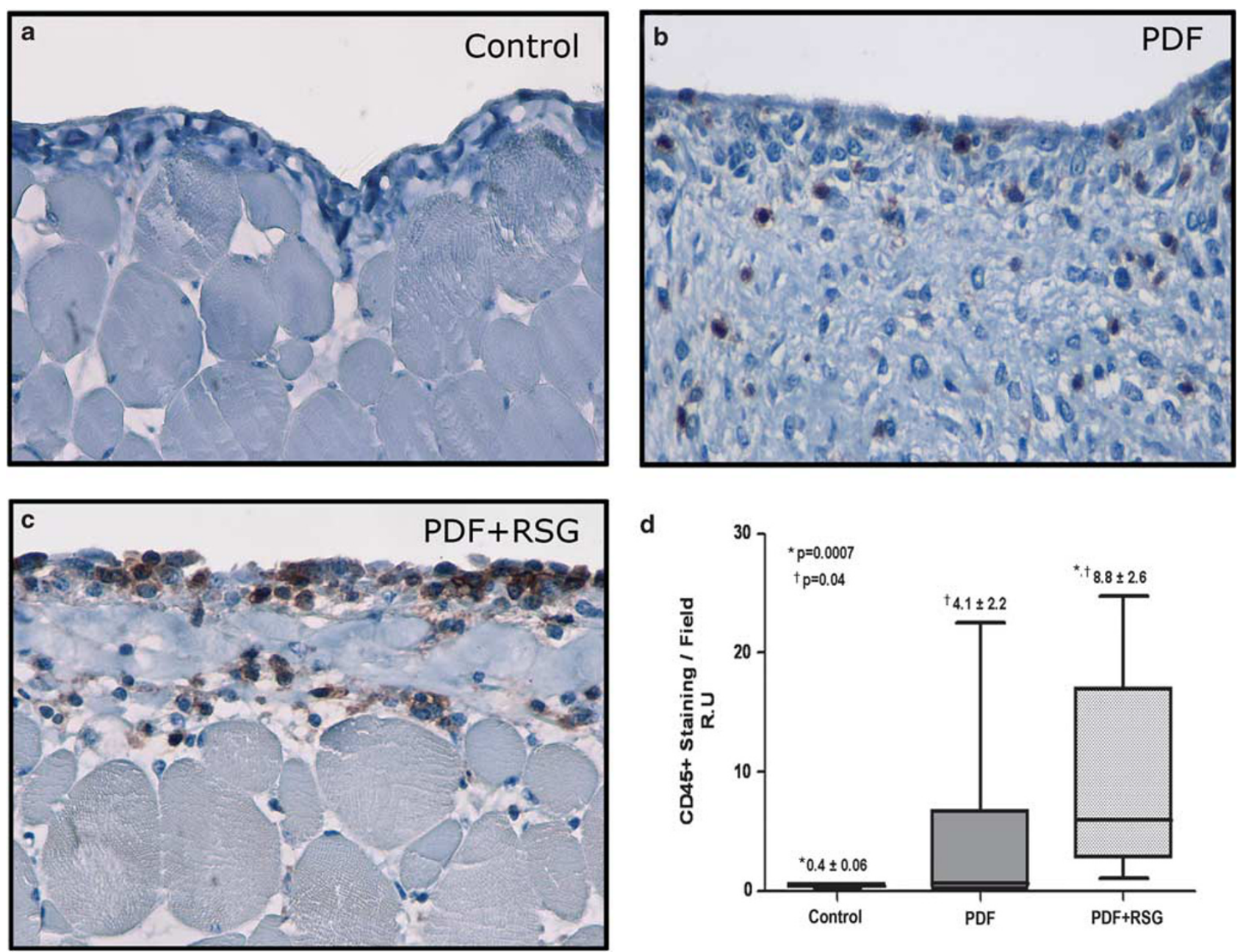

Figure 6 Effect of RSG treatment on submesothelial recruitment of CD45 cells. Mice received a daily instillation of standard PD fluid for 3 weeks with or without the oral adminstraton of RSG (PDF, $n=12$ and PDF + RSG $n=11$ ). A control group of mice that were not surgically treated and that received no fluid was also included (control; $n=5$ ). (a-c) Leukocyte infiltration increases in PD fluid-instilled mice compared with control mice, although not to a statistically significant extent. Administration of RSG significantly enhanced the CD45 ${ }^{+}$in cellular infiltrates compared with the control and PDF groups. (d) Box plots of the median, minimum, and maximum, as well as the 25 th and 75 th percentile values. Numbers above boxes depict mean \pm s.e. The symbols represent the statistical differences between groups. Magnification $\times 400$.

preserved the mesothelial cells monolayer and improved ultrafiltration, although the reduction of fibrosis and angiogenesis in visceral peritoneum was not statistically significant. ${ }^{34}$ However, these apparent discrepancies might reflect the different anatomical parts of the peritoneum analyzed in the two studies (parietal or visceral).

The evidence currently emerging indicates that MMT of the mesothelial cells is an important process in the accumulation of myofibroblasts in the submesothelial compact zone. In addition, it has been demonstrated that the presence of transdifferentiated mesothelial cells, either in PD effluent or in the peritoneal tissue, is associated with high transport status of the peritoneal membrane. ${ }^{14-16}$ Our data demonstrate that some myofibroblasts located in the compact zone of mice treated with PD fluid express cytokeratin, indicative of their mesothelial origin via MMT. Interestingly, treatment with RSG almost completely abolishes the accumulation of myofibroblasts and partially preserves the mesothelium. These data indicate that RSG treatment interferes with the process of MMT in vivo. By contrast, in cell culture experiments RSG is unable to block TGF- $\beta 1$-induced MMT of omentum mesothelial cells or to reverse the mesenchymal phenotype of effluent-derived mesothelial cells. In our previous studies, in an attempt to mimic the complex mixture of pro-inflammatory and pro-fibrotic stimuli induced during $\mathrm{PD}$, we used a combination of TGF- $\beta 1$ and IL- $1 \beta$ to induce MMT in vitro. ${ }^{10,14,15,44}$ We demonstrated that the treatment of mesothelial cells with TGF- $\beta 1$ is sufficient to induce their mesenchymal conversion, and that the combination of TGF$\beta 1$ and IL- $1 \beta$ has additive effect on the MMT process. ${ }^{10,44}$ In this study, we demonstrate that RSG does not block the MMT induced by TGF- $\beta 1$ alone, thus it is not expected that 
a

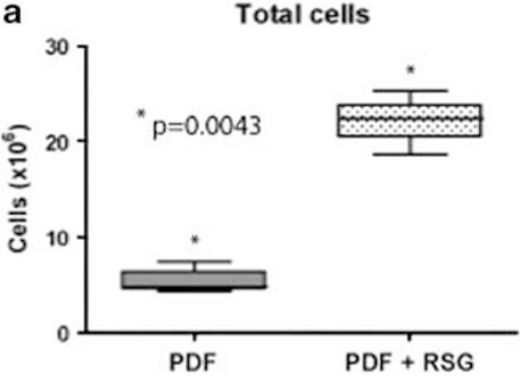

C

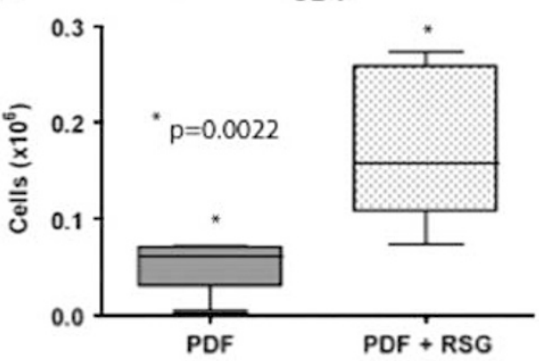

e

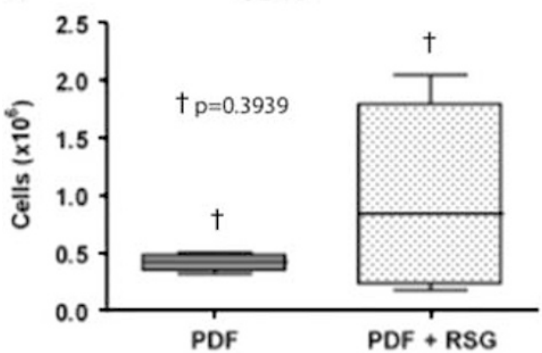

b

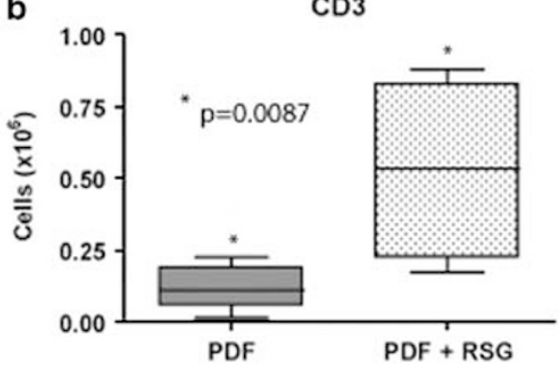

d

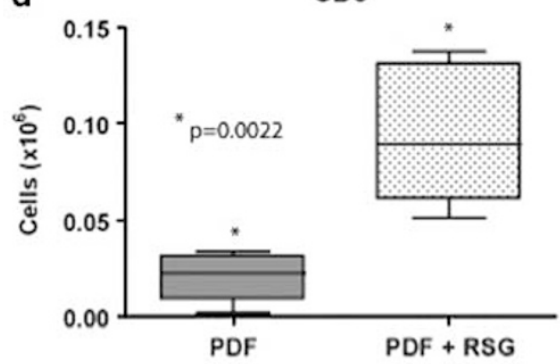

f

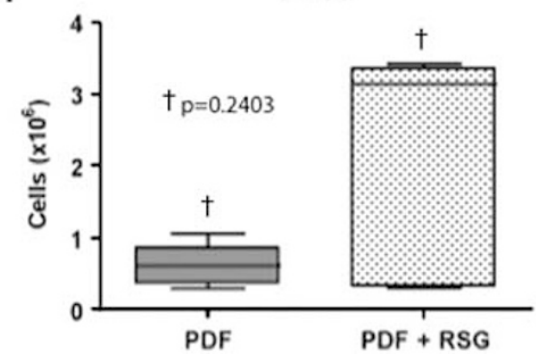

Figure 7 Effect of RSG treatment on peritoneal influx of leukocytes. (a) Analysis of leukocytes in the drained volumes shows a significant increase of total cell count in PD fluid-instilled animals that received RSG (PDF + RSG; $n=5$ ) when compared with mice treated with PD fluid alone (PDF; $n=7$ ). (b-d) The increase in cell influx is significant for total T-cells $\left(\mathrm{CD}^{+}\right)$, and for both the $\mathrm{CD} 4^{+}$and $\mathrm{CD} 8{ }^{+}$T-lymphocyte populations. (e and f) The increases in B-lymphocytes $\left(\mathrm{CD} 19^{+}\right)$and macrophages $\left(\mathrm{F} 4 / 80^{+}\right)$were not significantly different. Box plots of the median, minimum, and maximum, as well as the 25 th and 75 th percentile values. The symbols represent the statistical differences between groups.

PPAR- $\gamma$ activation might affect the MMT triggered by a stronger stimulus such as TGF- $\beta 1$ plus IL- $1 \beta$. In agreement with our results, Yao et al have shown that RSG-treatment itself does not prevent glucose-induced mesenchymal-like conversion of mesothelial cells in vitro, and that is a combination of RSG and angitensin II receptor blocker to decrease the MMT-like process necessary. ${ }^{45}$ It is worthwhile to point out that MMT in vivo may result from an integration of diverse signals triggered by multiple factors, being difficult to assign priorities or hierarchy. Thus, it is tempting to speculate that RSG prevents MMT in vivo by reducing various MMTpromoting stimuli, such as AGEs and/or inflammation.

Using anti-RAGE antibodies in uremic rats or RAGEdeficient mice, it has been demonstrated that AGE-RAGE interaction has a key role in peritoneal damage induced by uremia and PD fluid exposure. ${ }^{46,47}$ Mesothelial cells also express RAGE ${ }^{48}$ and AGEs stimulate the production of matrix components by these cells as well as the synthesis of cytokines and growth factors, such as TGF- $\beta$ and VEGF., ${ }^{99-52}$
AGEs may also induce MMT in vitro and in vivo, ${ }^{46,50,51}$ and they can reduce cell proliferation and induce mesothelial cells apoptosis. $^{53}$ Here, we demonstrate that RSG-treatment decreases the peritoneal accumulation of AGEs in PD fluidinstilled mice. The mechanisms by which RSG reduces the peritoneal accumulation of AGEs are not yet clearly defined and it might just be a consequence of its effect in lowering glucose. In this regard, we observed that PD fluid-exposed mice treated with RSG show a significant decrease of the glucose concentrations in sera when compared with animals treated with PD fluid alone. The partial normalization of glucose levels in animals treated with RSG could be due to its systemic glucose-lowering effect and to a decreased glucose load through the peritoneal membrane. It could be hypothesized that RSG might ameliorate the peritoneal diabetic environment and as a consequence, induce a reduction of structural protein glycation. In fact, it has been shown that RSG administration to diabetic patients decreases the circulating levels of glycated hemoglobin. ${ }^{54}$ The decrease of peritoneal AGEs in PD fluid 
a

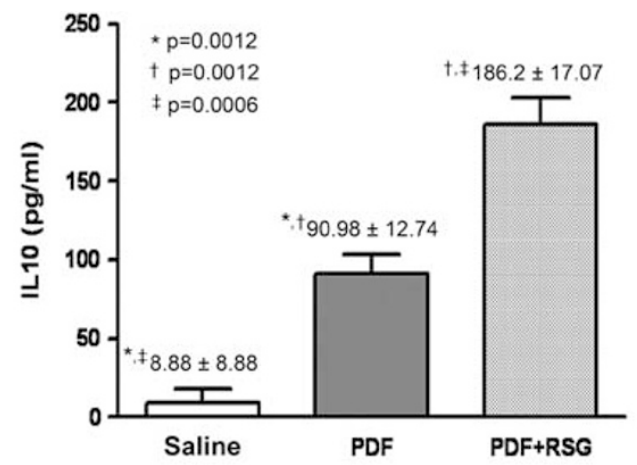

b
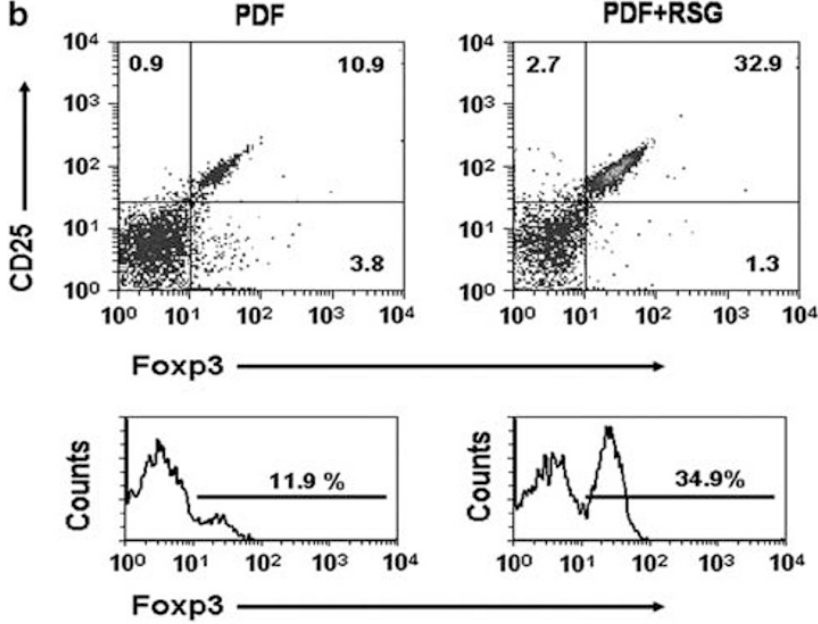

C

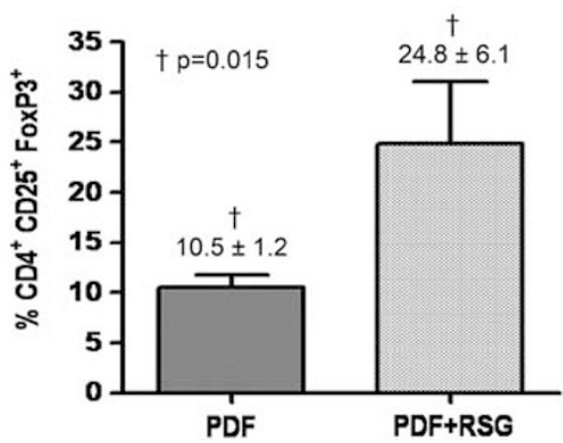

Figure 8 RSG treatment further induces IL-10 production and increases regulatory $\mathrm{T}$ cell population in the peritoneal cavity. (a) IL-10 concentration increases in the drained volumes of animals instilled with PD fluid (PDF; $n=12$ ) when compared with mice instilled with saline solution (saline; $n=7$ ). Administration of RSG to animals instilled with PD fluid (PDF + RSG; $n=11)$ further enhanced the concentration of IL-10 reaching significant differences when compared with both saline and PDF groups. Bars graphic depict mean \pm s.e. Symbols represent the statistic differences between groups. (b) Flow cytometry of CD25 and FoxP3 expression in total gated $\mathrm{CD}^{+}{ }^{+} \mathrm{T}$ cells isolated from the peritoneal cavity of a PD fluid-instilled mouse and from a PD fluid-instilled mouse treated with RSG. Numbers depict the proportions of $\mathrm{CD}_{2} 5^{+}$and/or FoxP3 ${ }^{+}$cells in each panel (upper panels). Histograms represent the total percentages of FoxP3 ${ }^{+}$cells in each case (lower panels). A representative mouse of each PDF and PDF + RSG groups is shown. (c) Proportions of $\mathrm{CD}^{+}{ }^{+} \mathrm{CD} 25^{+} \mathrm{FoxP}^{+}$cells in PD fluidinstilled mice (PDF; $n=5)$ and in PD fluid-instilled mice treated with RSG (PDF + RSG; $n=6$ ). Bars depict mean \pm s.e. and symbol represents the statistical difference between groups. instilled mice fits well with the observed reduction of MMT, fibrosis and angiogenesis, and with the preservation of the mesothelium in vivo. Furthermore, the better preservation of the mesothelium may also be explained by a direct effect of RSG on mesothelial cell survival, as witnessed in vitro by analyzing apoptosis.

Besides the accumulation of AGEs, the high glucose content of PD fluids 'per se' may also promote peritoneal damage by activating abdominal fat tissue. ${ }^{55}$ In this context, adipocytes exposed to glucose produce leptin, which in turn promotes TGF- $\beta$ production by mesothelial cells ${ }^{56}$ and cooperates with TGF- $\beta$ in the induction of MMT of mesothelial cells. ${ }^{57}$ In consequence, it might be expected to find high leptin levels in PD effluents. PPAR- $\gamma$ agonists are implicated in glucose and lipid metabolism and thus, we hypothesize that RSG might modulate the leptin production by peritoneal fat tissue. However, we found similarly high levels of leptin in PD effluents from mice independent of whether they were treated with RSG (data not shown), suggesting that the protection offered by RSG was not related with changes in the activation of adipose tissue.

Another upstream stimulus that promotes MMT during PD fluid exposure is inflammation. PPAR- $\gamma$ agonists have anti-inflammatory properties and these drugs are capable of downregulating most cells in the innate and adaptive immune system, ${ }^{22-25}$ and of activating a regulatory T-cell response. ${ }^{26,27}$ Our data demonstrate that administration of RSG enhances the recruitment of leukocytes to the peritoneal cavity of PD fluid-instilled mice. The increase in cell influx is significant for both $\mathrm{CD}^{+}{ }^{+}$and $\mathrm{CD} 8^{+}$T-cells but not for B-lymphocytes or macrophages. Interestingly, RSG administration increases the population of $\mathrm{CD}^{+} \mathrm{CD} 25^{+}$ regulatory $\mathrm{T}$ cells in the peritoneal cavity of $\mathrm{PD}$ fluid-instilled mice. Two general subsets of regulatory $\mathrm{T}$ cells (natural and induced) have been described, which develop intrathymically and extrathymically, respectively. ${ }^{58}$ Natural regulatory T cells, that constitute $90 \%$ of the peripheral $\mathrm{CD} 4{ }^{+} \mathrm{CD} 25^{+}$subset, are characterized by their expression of the transcription factor FoxP3 and are fully functional upon thymic export. By contrast, the immunosuppressive function of induced regulatory $\mathrm{T}$ cells is acquired in the periphery from naive $\mathrm{CD} 4^{+}$ $\mathrm{CD} 25^{-} \mathrm{T}$ cell precursors. Induced regulatory $\mathrm{T}$ cells can be subdivided on the basis of their expression of FoxP3 into two subsets: $\mathrm{CD} 4{ }^{+} \mathrm{CD} 25^{+} \mathrm{FoxP}^{+}$and $\mathrm{CD} 4{ }^{+} \mathrm{CD} 25^{+}{ }^{-} \mathrm{FoxP}^{-}$ (or $\operatorname{Tr} 1$ ). In addition, subsets of $\mathrm{CD}^{+}{ }^{+} \mathrm{T}$ cells with regulatory activity have been described. Recent studies have found that $\mathrm{CD} 8{ }^{+}$precursors can be induced to express FoxP3, with acquisition of induced regulatory $\mathrm{T}$ cell activity similar to $\mathrm{CD} 4{ }^{+} \mathrm{CD} 25^{+}$FoxP3 $^{+}$cells. ${ }^{58,59}$ In this study, we show that the administration of RSG enhances the expression of FoxP3 in the peritoneal cellular influx. The relative proportion of these $\mathrm{FoxP}^{+}$cells that derive from natural or induced regulatory $\mathrm{T}$ cells will require further analysis. All types of regulatory $\mathrm{T}$ cells, specially $\operatorname{Tr} 1$ cells, can produce the antiinflammatory cytokine IL-10. ${ }^{58}$ Accordingly, in the drained 
a
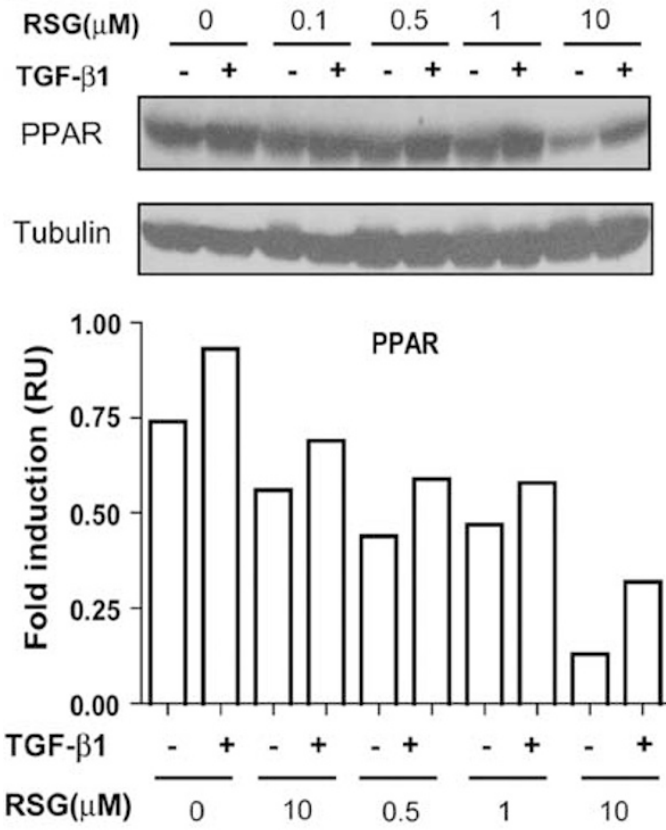

b
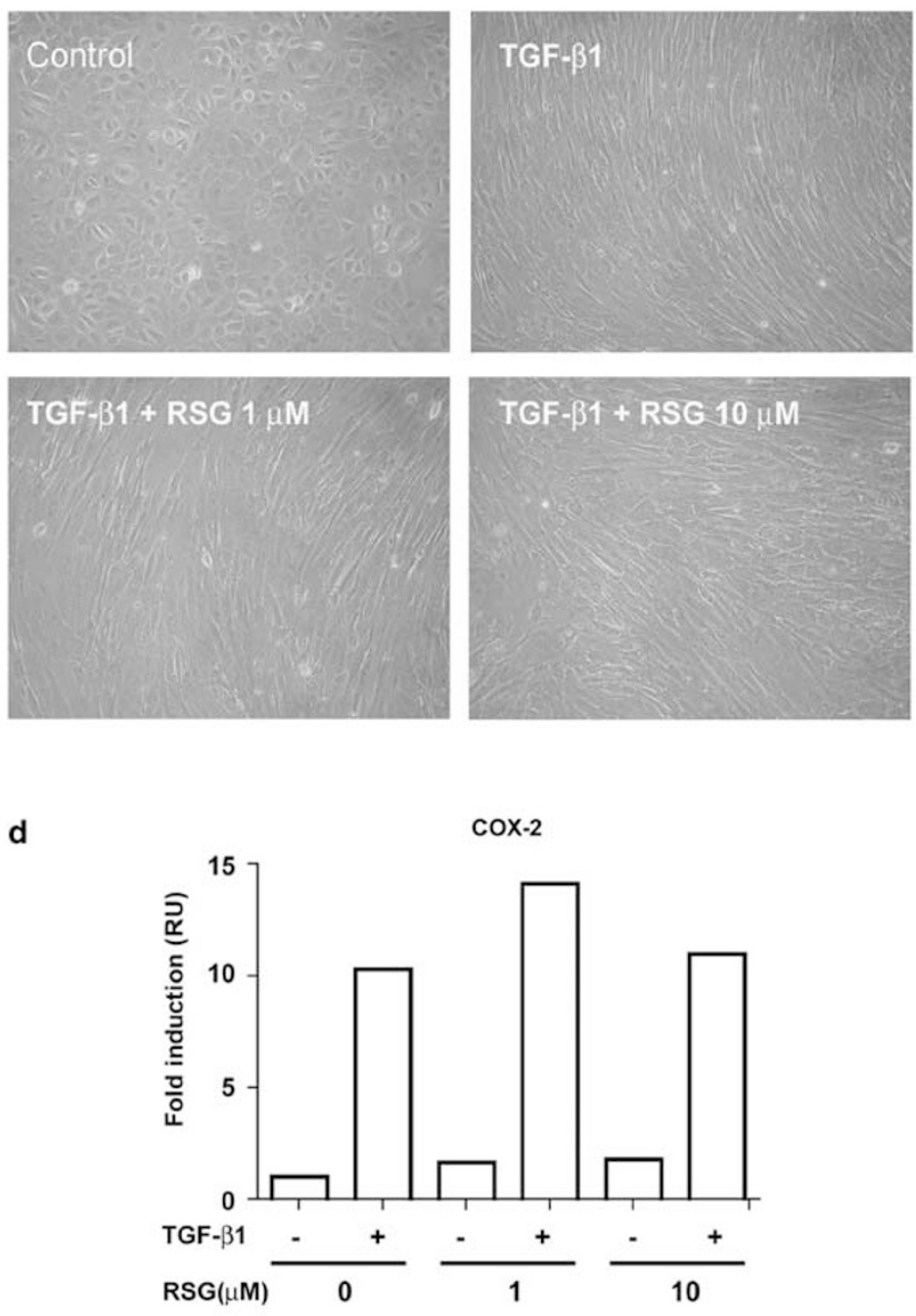

d VEGF
C

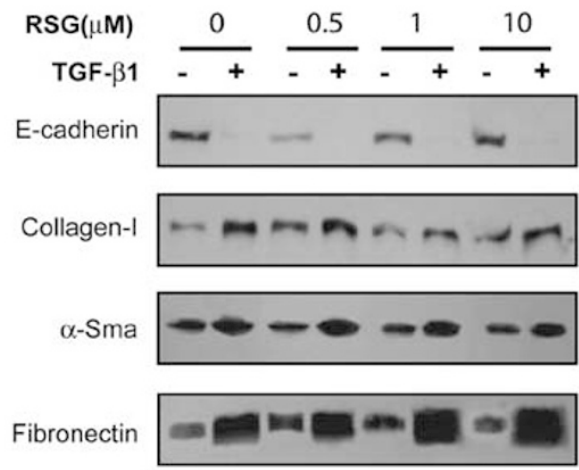

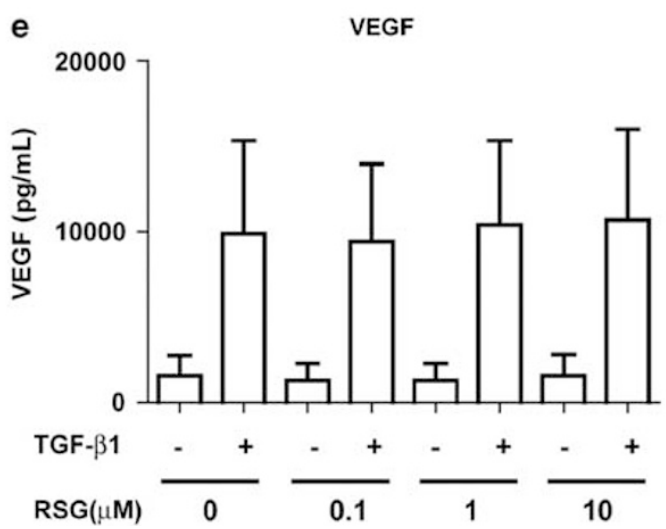

Figure 9 RSG treatment does not affect the MMT of mesothelial cells in vitro induced by TGF- $\beta$. Omentum-derived mesothelial cells were treated or not for $48 \mathrm{~h}$ with TGF- $\beta$ in the presence of different doses of RSG $(0.1-10 \mu \mathrm{M})$. (a) Western blot analysis shows that mesothelial cells express high levels of PPAR- $\gamma$ and that its expression is downregulated by RSG in a dose-dependent manner. Exposure to TGF- $\beta 1$ induces PPAR- $\gamma$ expression in mesothelial cells treated with different doses of RSG. (b) Phase-contrast microscopy demonstrates that RSG treatment ( 1 and $10 \mu \mathrm{M})$ does not prevent non-epithelioid phenotype acquisition of mesothelial cells. (c) Western blot analysis shows that RSG treatment $(0.5,1$, and $10 \mu \mathrm{M})$ does not prevent E-cadherin downregulation, and it does not affect the upregulation of the MMT-associated molecules $\alpha \mathrm{SMA}$, collagen I, and fibronectin. (d) Quantitative RT-PCR shows that RSG treatment (1 and $10 \mu \mathrm{M}$ ) does not block the induction of the pro-inflammatory molecule COX-2. (e) RSG treatment $(0.1,1$, and $10 \mu \mathrm{M})$ does not affect the upregulation of the pro-angiogenic factor VEGF as determined by ELISA. Bars in panel $\mathbf{d}$ depict a representative experiment and in panel e represent mean \pm s.d. of three independent experiments. 

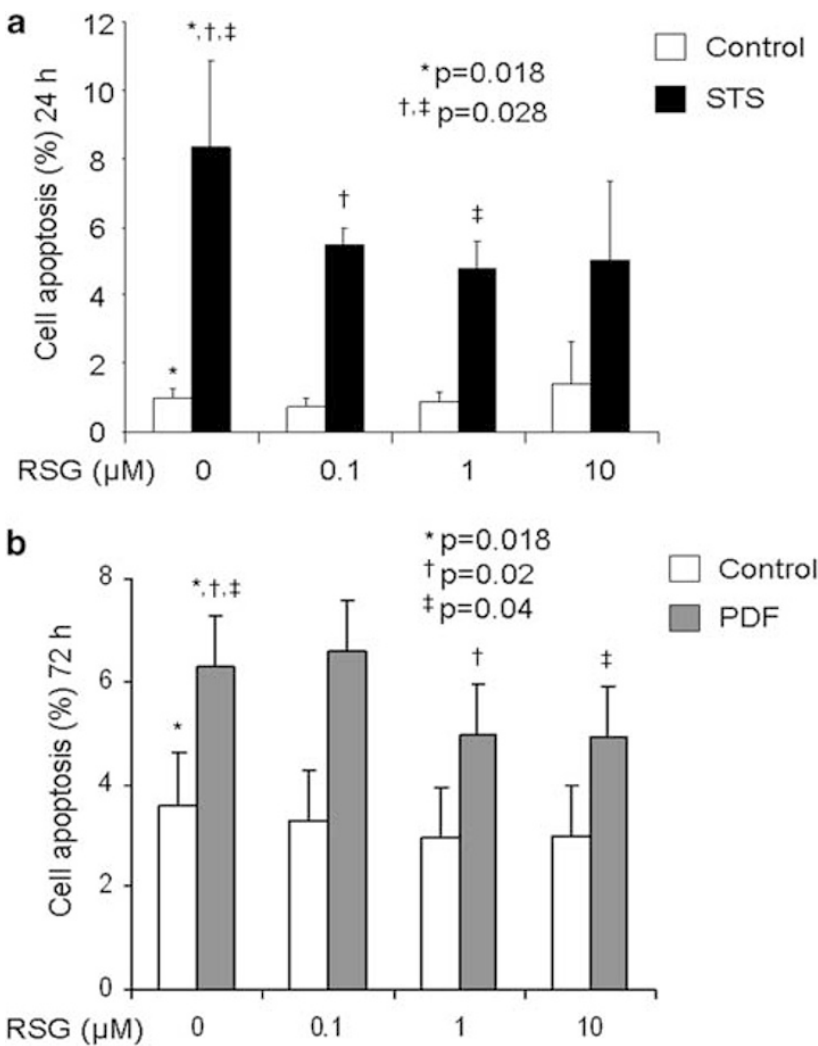

Figure 10 Effect of RSG on mesothelial cells apoptosis in-vitro. Mesothelial cells were cultured to subconfluence, rested in serum-free media for $24 \mathrm{~h}$ and then treated with two apoptotic stimuli Staurosporine and standard PD fluid, in the absence or presence of RSG $(0.1,1$, and $10 \mu \mathrm{M})$. Flow cytometry assessment of DNA content shows that treatment with different doses of RSG decreases apoptosis of cells treated with $100 \mathrm{nM}$ Staurosporine during $24 \mathrm{~h}$ (a) and of cells exposed to PD fluid $(4.25 \%$ glucose, stay safe; Fresenius) during $72 \mathrm{~h}$ (b). Bars depict mean \pm s.d. of four independent experiments made in triplicate. Symbols represent the statistical differences.

volumes from PD fluid-instilled mice treated with RSG there is a significant increase in IL-10 when compared with animals treated with PD fluid alone, whereas other cytokines do not change significantly. It is noteworthy, however, that there is a tendency to decrease the peritoneal levels of the proinflammatory cytokines IL- 6 and IL-17 and to increase the levels of the anti-inflammatory cytokine IL-4 in the group treated with RSG. Although a better characterization of the immunoinflammatory response in RSG-treated animals would be required and deserves further studies, our results suggest that RSG administration triggers an antiinflammatory response mediated by regulatory T-cells.

In conclusion, we show that administration of RSG to mice exposed to PD fluid produce pleiotropic protective effects on the peritoneal membrane, reducing AGEs formation and inflammation, as well as preserving mesothelial cell monolayer. Our data indicate that PPAR- $\gamma$ activation might be a suitable strategy to ameliorate peritoneal deterioration in PD patients. We are aware that PPAR- $\gamma$ agonists cannot be easily employed in the clinical practice of $\mathrm{PD}$, at least for long-term treatments, because several adverse effects have been described for these drugs. ${ }^{60}$ This issue is particularly important in patients with end-stage renal diseases who obviously have impoverished renal clearance capacity. ${ }^{61}$ However, RSG may be considered as a safe drug for use in uremic status because it is metabolized in the liver and thus, the accumulation of the drug and the risk of severe and prolonged hypoglycemia are minimized. ${ }^{62}$ We believe that our results provide evidence that inflammation can be considered as a potential therapeutic target to ameliorate PDrelated peritoneal membrane deterioration. Further studies of peritoneal inflammatory reaction will lead to the generation of more specific interventions with minimal side effects.

Supplementary Information accompanies the paper on the Laboratory Investigation website (http://www.laboratoryinvestigation.org)

\section{ACKNOWLEDGEMENTS}

This work was supported by grants SAF2007-61201 and PET2006-0256 from the 'Ministerio de Ciencia e Innovación' to ML-C, by grants from 'Fondo de Investigaciones Sanitarias' (FIS) PI 06/0098 to R.S, PI 07/00126 to AA and from RETICS 06/0016 to RS, MR-O and AO. This work was also partially supported by Fresenius Medical Care, Gambro Europe and Baxter Healthcare Corp (The Baxter Extramural Grant Program 2007). We thank the nurses at the peritoneal dialysis units for help in recovering the peritoneal effluents and omental samples. We also thank Patricia Albar-Vizcaíno and Francisca Molina for assistance in cell-culture experiments, and Javier Benito de la Víbora and Carlota Largo Aramburu for the assistance with mouse care.

\section{DISCLOSURE/CONFLICT OF INTEREST}

The authors declare no conflict of interest.

1. Krediet RT. The peritoneal membrane in chronic peritoneal dialysis. Kidney Int 1999;55:341-356.

2. Krediet RT, Lindholm B, Rippe B. Pathophysiology of peritoneal membrane failure. Perit Dial Int 2000;20(Suppl 4):S22-S42.

3. Aroeira LS, Aguilera A, Sanchez-Tomero JA, et al. Epithelial to mesenchymal transition and peritoneal membrane failure in peritoneal dialysis patients: pathologic significance and potential therapeutic interventions. J Am Soc Nephrol 2007;18:2004-2013.

4. Yung S, Chan TM. Intrinsic cells: mesothelial cells - central players in regulating inflammation and resolution. Perit Dial Int 2009;29(Suppl 2): S21-S27.

5. Williams JD, Craig KJ, Topley N, et al. Morphologic changes in the peritoneal membrane of patients with renal disease. J Am Soc Nephrol 2002;13:470-479.

6. Mateijsen MA, Van der Wal AC, Hendriks PM, et al. Vascular and interstitial changes in the peritoneum of CAPD patients with peritoneal sclerosis. Perit Dial Int 1999;19:517-525.

7. Plum J, Hermann S, Fusshöller A, et al. Peritoneal sclerosis in peritoneal dialysis patients related to dialysis settings and peritoneal transport properties. Kidney Int Suppl 2001;78:S42-S47.

8. Selgas $R$, Fernández-Reyes MJ, Bosque $E$, et al. Functional longevity of the human peritoneum: how long is continuous peritoneal dialysis possible? Results of a prospective medium long-term study. Am J Kidney Dis 1994;23:64-73.

9. Margetts PJ, Bonniaud P. Basic mechanisms and clinical implications of peritoneal fibrosis. Perit Dial Int 2003;23:530-541.

10. Yáñez-Mo $M$, Lara-Pezzi $E$, Selgas $R$, et al. Peritoneal dialysis and epithelial-to-mesenchymal transition of mesothelial cells. N Engl J Med 2003;348:403-413.

11. Yang $A H$, Chen JY, Lin JK. Myofibroblastic conversion of mesothelial cells. Kidney Int 2003;63:1530-1539.

12. Jiménez-Heffernan JA, Aguilera A, Aroeira LS, et al. Immunohistochemical characterization of fibroblast subpopulations in normal 
peritoneal tissue and in peritoneal dialysis-induced fibrosis. Virchows Arch 2004;444:247-256.

13. Aguilera A, Yáñez-Mo $M$, Selgas $R$, et al. Epithelial to mesenchymal transition as a triggering factor of peritoneal membrane fibrosis and angiogenesis in peritoneal dialysis patients. Curr Opin Investig Drugs 2005;6:262-268

14. Aroeira LS, Aguilera A, Selgas R, et al. Mesenchymal conversion of mesothelial cells as a mechanism responsible for high solute transport rate in peritoneal dialysis: role of vascular endothelial growth factor. Am J Kidney Dis 2005;46:938-948.

15. Aroeira LS, Lara-Pezzi E, Loureiro J, et al. Cyclooxygenase-2 mediates dialysate-induced alterations of the peritoneal membrane. J Am Soc Nephrol 2009;20:582-592.

16. Del Peso G, Jiménez-Heffernan JA, Bajo MA, et al. Epithelial-tomesenchymal transition of mesothelial cells is an early event during peritoneal dialysis and is associated with high peritoneal transport. Kidney Int Suppl 2008;108:S26-S33.

17. Rosenberg ME. Peritoneal dialysis: diabetes of the peritoneal cavity. J Lab Clin Med 1999;134:103-104.

18. Goh SY, Cooper ME. Clinical review: The role of advanced glycation end products in progression and complications of diabetes. J Clin Endocrinol Metab 2008;93:1143-1152.

19. Rosen ED, Spiegelman BM. PPARgamma: a nuclear regulator of metabolism, differentiation, and cell growth. J Biol Chem 2001;276 37731-37734.

20. Bensinger SJ, Tontonoz P. Integration of metabolism and inflammation by lipid-activated nuclear receptors. Nature 2008;454:470-477.

21. Yki-Järvinen H. Thiazolidinediones. N Engl J Med 2004;351:1106-1118.

22. Ricote $\mathrm{M}$, Li AC, Willson TM, et al. The peroxisome proliferatoractivated receptor-gamma is a negative regulator of macrophage activation. Nature 1998;391:79-82.

23. Castrillo A, Tontonoz P. Nuclear receptors in macrophage biology: at the crossroads of lipid metabolism and inflammation. Annu Rev Cell Dev Biol 2004;20:455-480.

24. Clark RB, Bishop-Bailey D, Estrada-Hernandez T, et al. The nuclear receptor PPAR gamma and immunoregulation: PPAR gamma mediates inhibition of helper T cell responses. J Immunol 2000;164:1364-1371.

25. Daynes RA, Jones DC. Emerging roles of PPARs in inflammation and immunity. Nat Rev Immunol 2002;2:748-759.

26. Hontecillas R, Bassaganya-Riera J. Peroxisome proliferator-activated receptor gamma is required for regulatory CD4+ T cell-mediated protection against colitis. J Immunol 2007;178:2940-2949.

27. Wohlfert EA, Nichols FC, Nevius E, et al. Peroxisome proliferatoractivated receptor gamma (PPARgamma) and immunoregulation enhancement of regulatory T cells through PPARgamma-dependent and -independent mechanisms. J Immunol 2007;178:4129-4135.

28. Li Y, Wen X, Spataro BC, et al. Hepatocyte growth factor is a downstream effector that mediates the antifibrotic action of peroxisome proliferator-activated receptor-gamma agonists. J Am Soc Nephrol 2006;17:54-65.

29. Kawai T, Masaki T, Doi $\mathrm{S}$, et al. PPAR- $\gamma$ agonist attenuates renal interstitial fibrosis and inflammation through reduction of TGF- $\beta$. Lab Invest 2009;89:47-58.

30. Ko GJ, Kang YS, Han SY, et al. Pioglitazone attenuates diabetic nephropathy through an anti-inflammatory mechanism in type 2 diabetic rats. Nephrol Dial Transplant 2008;23:2750-2760.

31. Toblli JE, Ferrini MG, Cao G, et al. Antifibrotic effects of pioglitazone on the kidney in a rat model of type 2 diabetes mellitus. Nephrol Dial Transplant 2009;24:2384-2391.

32. Pistrosch F, Herbrig $\mathrm{K}$, Kindel $\mathrm{B}$, et al. Rosiglitazone improves glomerular hyperfiltration, renal endothelial dysfunction, and microalbuminuria of incipient diabetes nephropaty in patientes. Diabetes 2005;54:2206-2211.

33. Bozkurt D, Taskin H, Sezak $M$, et al. Rosiglitazone, a peroxisome proliferator-activated receptor agonist, improves peritoneal alteration resulting from an encapsulated peritoneal sclerosis model. Adv Perit Dial 2008;24:32-38.

34. Yao Q, Pawlaczyk K, Ayala ER, et al. Peroxisome proliferator-activated receptor-gamma agonists diminish peritoneal functional and morphological changes induced by bioincompatible peritoneal dialysis solution. Blood Purif 2006;24:575-582.

35. González-Mateo GT, Loureiro J, Jiménez-Hefferman JA, et al. Chronic exposure of mouse peritoneum to peritoneal dialysis fluid: structural and functional alterations of the peritoneal membrane. Perit Dial Int 2009;29:227-230.

36. Catalan MP, Reyero A, Egido J, et al. Acceleration of neutrophil apoptosis by glucose-containing peritoneal dialysis solutions: role of caspases. J Am Soc Nephrol 2001;12:2442-2449.

37. Justo P, Lorz C, Sanz A, et al. Intracellular mechanisms of cyclosporin A-induced tubular cell apoptosis. J Am Soc Nephrol 2003;14: 3072-3080.

38. Na HK, Surh YJ. Peroxisome proliferator-activated receptor gamma (PPAR-gamma) ligands as bifunctional regulator of cell proliferation. Biochem Pharmacol 2003;66:1381-1391.

39. Ren $Y$, Sun $C$, Sun $Y$, et al. PPAR gamma protects cardiomyocytes against oxidative stress and apoptosis via $\mathrm{Bcl}-2$ upregulation. Vascul Pharmacol 2009;51:169-174.

40. Wu JS, Lin TN, Wu KK. Rosiglitazone and PPAR-gamma overexpression protect mitochondrial membrane potential and prevent apoptosis by upregulating anti-apoptotic $\mathrm{Bcl}-2$ family proteins. J Cell Physiol 2009;220:58-71.

41. Kwon $\mathrm{CH}$, Park JY, Kim TH, et al. Ciglitazone induces apoptosis via activation of p38 MAPK and AIF nuclear translocation mediated by reactive oxygen species and $\mathrm{Ca}(2+)$ in opossum kidney cells. Toxicology 2009;257:1-9.

42. Sun $\mathrm{WH}, \mathrm{Chen} \mathrm{GS}, \mathrm{Ou} \mathrm{XL}$, et al. Inhibition of COX-2 and activation of peroxisome proliferator-activated receptor gamma synergistically inhibits proliferation and induces apoptosis of human pancreatic carcinoma cells. Cancer Lett 2009;275:247-255.

43. Kwon $\mathrm{CH}$, Yoon CS, Kim YK. Ciglitazone induces caspase-independent apoptosis via p38-dependent AIF nuclear translocation in renal epithelial cells. Toxicology 2008;244:13-24.

44. Strippoli R, Benedicto I, Pérez Lozano ML, et al. Epithelial-tomesenchymal transition of peritoneal mesothelial cells is regulated by an ERK/NF-kappaB/Snail1 pathway. Dis Model Mech 2008;1: 264-274.

45. Yao Q, Ayala ER, Qian JQ, et al. A combination of a PPAR-gamma agonist and an angiotensin II receptor blocker attenuates proinflammatory signaling and stimulates expression of Smad7 in human peritoneal mesothelial cells. Clin Nephrol 2007;68:295-301.

46. De Vriese AS, Tilton RG, Mortier $\mathrm{S}$, et al. Myofibroblast transdifferentiation of mesothelial cells is mediated by RAGE and contributes to peritoneal fibrosis in uraemia. Nephrol Dial Transplant 2006;21:2549-2555.

47. Schwenger V, Morath C, Salava A, et al. Damage to the peritoneal membrane by glucose degradation products is mediated by the receptor for advanced glycation end-products. J Am Soc Nephrol 2006;17:199-207.

48. Boulanger $\mathrm{E}$, Wautier MP, Wautier $\mathrm{JL}$, et al. AGEs bind to mesothelia cells via RAGE and stimulate VCAM-1 expression. Kidney Int 2002;61:148-156.

49. Boulanger E, Grossin N, Wautier MP, et al. Mesothelial RAGE activation by AGEs enhances VEGF release and potentiates capillary tube formation. Kidney Int 2007;71:126-133.

50. Hirahara I, Ishibashi $Y$, Kaname $S$, et al. Methylglyoxal induces peritoneal thickening by mesenchymal-like mesothelial cells in rats. Nephrol Dial Transplant 2009;24:437-447.

51. Conti G, Amore A, Cirina P, et al. Glycated adducts induce mesothelial cell transdifferentiation: role of glucose and icodextrin dialysis solutions. J Nephrol 2008;21:426-437.

52. Nevado J, Peiró C, Vallejo S, et al. Amadori adducts activate nuclear factor-kappaB-related proinflammatory genes in cultured human peritoneal mesothelial cells. Br J Pharmacol 2005;146:268-279.

53. Boulanger $E$, Wautier MP, Gane $P$, et al. The triggering of human peritoneal mesothelial cell apoptosis and oncosis by glucose and glycoxydation products. Nephrol Dial Transplant 2004;19:2208-2216.

54. Goldberg RB, Kendall DM, Deeg MA, et al. A comparison of lipid and glycemic effects of pioglitazone and rosiglitazone in patients with type 2 diabetes and dyslipidemia. Diabetes Care 2005;28:1547-1554.

55. Axelsson J, Carrero JJ, Avesani CM, et al. Adipokine signaling in the peritoneal dialysis patient. Contrib Nephrol 2006;150:166-173.

56. Leung JC, Chan LY, Tang SC, et al. Leptin induces TGF-beta synthesis through functional leptin receptor expressed by human peritoneal mesothelial cell. Kidney Int 2006;69:2078-2086.

57. Yang $\mathrm{AH}$, Huang SW, Chen JY, et al. Leptin augments myofibroblastic conversion and fibrogenic activity of human peritoneal mesothelial 
cells: a functional implication for peritoneal fibrosis. Nephrol Dia Transplant 2007;22:756-762.

58. Maynard CL, Weaver CT. Diversity in the contribution of IL-10 to T-cellmediated immune regulation. Immunol Rev 2008;226:219-233.

59. Kapp JA, Honjo K, Kapp LM, et al. TCR transgenic CD8+ T cells activated in the presence of TGFbeta express FoxP3 and mediate linked suppression of primary immune responses and cardiac allograft rejection. Int Immunol 2006;18:1549-1562.
60. Rizos CV, Elisaf MS, Mikhailidis DP, et al. How safe is the use of thiazolidinediones in clinical practice? Expert Opin Drug Saf 2009; 8:15-32.

61. Aramwit $P$, Supasyndh $O$, Sriboonruang T. Pharmacokinetics of singledose rosiglitazone in chronic ambulatory peritoneal dialysis patients. J Clin Pharm Ther 2008;33:685-690.

62. Iglesias $P$, Díez JJ. Peroxisome proliferator-activated receptor gamma agonists in renal disease. Eur J Endocrinol 2006;154:613-621. 